
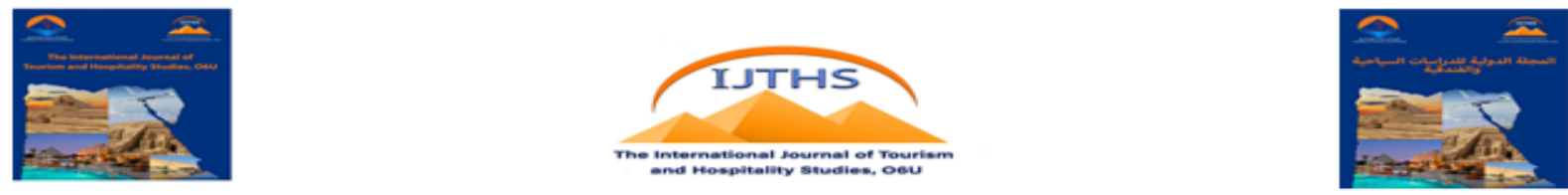

\title{
تقييم دور المكاتب الخارجية في استعادة الصورة الذهنية للمقصد السياحي المصري خلال الأزمات
}

أ. أحمد حسن علي الأسمر كلية السياحة والفنادق جامعه المنصورة- مصر
أ.د// دعاء سمير محمد حزه كلية السياحة والفنادق جامعd المنصورة- مصر
أ.د/ عزة سعد محمد عطية

كلية السياحة والفنادق جامعه 7 أكتوير - مصر

\footnotetext{
الملخص

تهدف تلك الدراسة إلى تفعيل دور المكاتب الخارجية للهيئة المصرية العامة للتنشيط السياحي في استعادة الصورة الذهنية للمقصد السياحي خلال الأزمات. وتعتمد الدراسة الحالية علي المنهج الوصفي التحليلي من خلال استعراض الدراسات النظرية المتعلقة بموضوع الدراسة، وكذلك إجراء الدراسة الميدانية من

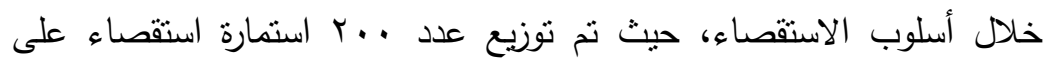
العاملين بالهيئة المصرية العامة للتنشيط السياحي وموظفي وزارة السياحة والعاملين بالمكاتب الخارجية وذلك بغرض التعرف علي توجهاتهم وأراءهم نحو وراني أبعاد الدراسة، وتم تحليل البيانات الواردة من الاستمارات الصالحة للتحليل الإحصائي وعددهم 1/1 استمارة باستخدام برنامج الحزم الإحصائية للعلوم الاجتماعية SPSS إصدار \& ع للوصول إلي نتائج الدراسة. توصلت الدراسة إلى أن المكاتب الخارجية لهيئة تتشيط السياحة تساهم بشكل رئيسي في تحسين

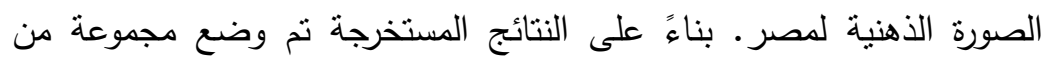
التوصيات أبرزها، زيادة عدد المكاتب الخارجية للهيئة المصرية العامة للتنشيط

معلومات المقالة

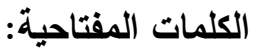

المكاتب الخارجية؛ الصورة

الذهنية؛ المقصد السياحي

المصري؛ الأزمات السياحية.

(IJTHS), O6U

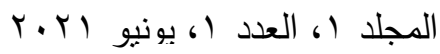

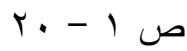


مقدمة

تقوم المكاتب الخارجية بدور فعال من أجل تدفق حركة السياحة الدولية لمصر بصفة عامة إلى جانب دراسة الأسواق السياحية وتحليلها للوقوف على نقاط القوة والضعف وكيفية اختيار الاستراتيجية المناسبة لكل سوق على حدة وينصب نشاط مكاتب السياحة الخارجية على الاتصال بالجماهير المختلفة وذللك بهدف الإعلام والإقناع عن طريق جهود الإعلان والعلاقات العامة والدعاية. (مرسي، ·. . ץ). وتتمثل بعض الأنشطة التي تقوم بها هذه المكاتب والتي يمكن استغلالها في تحسين الصورة الذهنية للسائح في التعرف على أهم مصادر حركة السياحة في السوق السياحي بالخارج عن طريق دراسة الأسواق السياحية

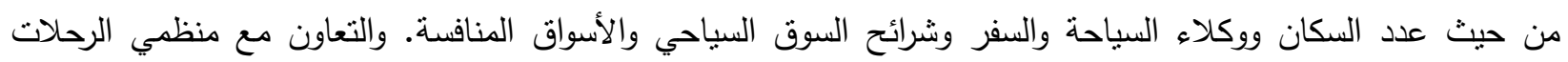
الثاملة ووكلاء السياحة ومدهم بكل المواد الدعائية التي تساعدهم على جذب السائحين لمصر ، كما أن موافاة هذه الثركات بالمعلومات الخاصة بالتسهيلات السياحية عن مصر باستمرار يعتبر مهمة رئيسية لتلك المكاتب وفي نفس الوقت إقناع منظمي رحلات ووكلاء سياحة جدد بإدراج مصر ضمن برامجهم السياحية. وتقوم المكاتب الخارجية بدور فعال في تحسين الصورة الذهنية للمقصد السياحي المصري خاصة أوقات الأزمات من خلال مساعدة المنظمات والمؤسسات والقيادات في رسم الخطط، واتخاذ القرارات التي تكون صورة إيجابية عن المقصد السياحي المصري التي تتفق مع احتياجات الجماهير المستهدفة. وتؤدي دوراً مهماً في إثراء أو تقديم الرؤية المتكاملة للاراسات الإعلامية والإدارية، وتناهم في تكوين وتشكيل الرأي العام تجاه المنظمات والمؤسسات في البلد المستهدف تحسين الصورة الذهنية للمقصد السياحي المصري به. (Soliman,

Wahba,2018)

مشكلة البحث

أثتتت بعض الدراسات والأبحاث اختلاف الصورة الذهنية لمصر بين جماهير الدول التي تم إجراء استطلاعات الرأي فيها، وقد تنين أن هناك درجة من التقصير من الجانب المصري فيما يخص بتحسين صورة مصر الذهنية أمام العالم الخارجي. (حسن، V ا • Y)، وتكمن مشكلة البحث في الاجابة علي التساؤلات التالية: ما هي الإجراءات التي تقوم بها المكاتب الخارجية للتسويق لمصر سياحياً خلال الازمات؟ وإلي أي مدي يتم تطبيقٌ نلك الخطط والاجراءات التي تساهم في تحسين الصورة الذهنية عن مصر خلال الازمات؟ وما هي الصعوبات والمعوقات التي قد نواجه تللك المكاتب أنثاء القيام بعطها؟

أهداف البحث

$$
\text { يستهدف البحث الوصول الي الاهداف الاتية: }
$$

ا. ت تحديد الدور الترويجي التي تقوم به تلك المكاثب لتحسين الصورة الذهنية خلال الازمات

$$
\text { r. معرفة مهارات وقدرات الموارد البشرية الموجودة بالمكاتب الخارجية }
$$

r. الإلمام بالأنشطة الني تقوم بها المكاتب الخارجية للتسويق لمصر سياحياً خلال الازمات

ع. تحديد مدي فاعليةٌ تطبيقُ تلك الخطط والاجراءات

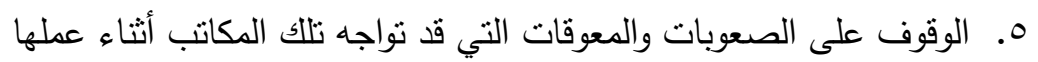




\section{فرضيات البحث}

\section{يقوم البحث على الفروض الآتية}

الفرض الأول: نوجد علاقة ارتباط طردية ذات دلالة إحصائية عند مستوي معنوية ه. . • بين الاككانات المادية والبشرية للمكاتب الخارجية وقدرتها علي تحسين الصورة الذهنية لمصر خلال الازمات الفرض الثاني: توجد علاقة ارتباط عكسية ذات دلالة إحصائية عند مسنوي معنوية ه.., • بين المعوقات التي نواجه المكاتب الخارجية وقدرتها علي تحسين الصورة الذهنية لمصر خلال الازمات الفرض الثالث: توجد علاقة ارتباط طرديـة ذات دلالة إحصائية عند مستوي معنوية ه ., · بين خطط واجراءات المكاتب السياحية وتحسين الصورة الذهنية لمصر خلال الازمات

محددات البحث

تتضمن الدراسة المحددات الآتية:

أ- المحدد المكاني: يوجد العديد من مكاتب مصر الخارجية للتنشيط السياحي حيث وصل عددهم في عام 17 • بم، بعد خفض التمثيل الخارجي لها ترشيدا للنفقات في دول العالم الرئيسية، من (V ( ) إلى (^) مكاتب فقط توجد في: (الهند، الصين، بريطانيا، إيطالبا، روسبا، ألمانيا، فرنسا، التشيك). ب- المحدد الزمنى: تحليل الدراسة الميدانية عن طريق توزيع استمارات الاستقصـاء وذلك خلال الفترة من 10 ديسمبر

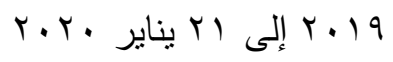

الإطار النظري للبحث المكاتب الخارجية للهيئة المصرية العامة للتشثيط السياحي

تعد الهيئة المصرية العامـة للتشبط السباحي أحد أهم أضـلاع التتظيم الاداري الحكومي السباحي في مصر باعتبارها هيئة حكومية خدمية هدفها الترويج للسياحة المصرية في الخارج. (البشبيشي، ب ا ب)

صدر القرار الجمهوري رقم ع ا لسنة ا919 ام بإنشاء الهيئة المصرية العامة للتنشيط السياحي وبموجب هذا القرار تم انشاء الهيئة المذكورة وهي ذات شخصية اعتبارية تابعة لوزير السياحة ومقرها مدينة القاهرة، وتهدف الهيئة إلي رفع معدلات النمو في حركة السياحة الدوليـة إلي مصـر وإبراز الصـورة الحقيقية لماضـي مصر الحضـاري ونهضتنها الحديثة ومقوماتها السياحية المختلفة، العمل علي إزالة المعوقات التي تعترض نمو الحركة السياحية، وتشجيع السياحة الداخلية وزيادة الوعي السياحي وربط المواطنين بنراثهم، ومن بين المهام الموكلة إلي الهيئة تقديم المعونة الفنية والتسويقية والتعاون والمساهمة مع الثركات والمنشآت في مجال تتشيط السياحة، ويتضـح من ذلك أنـه يمكن للمشروعات العاملة في مجال السباحة أن تستقيد من برامج تتشيط السياحة والجذب السياحي إلي مصر التي تعدها الهيئة، إلا أن دور الهيئة بالنسبة إلي هذه المشروعات يقتصر علي تقديم المعونة الفنية والتسويقية في مجال تتشيط السياحة، ولا يمتد إلي تقديم المعونة المالية أو المساهمة في تتفيذ البرامج السياحية، لئه 
كما تقوم الهيئة بتقديم خدمة استعلامية للجمهور عن المقومات السياحية في مصر وتتبعها لهذا الغرض مكاتب الاستعلامات

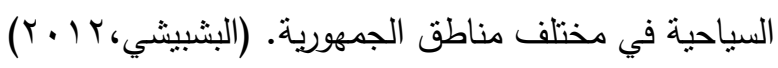

بناءً على قرار مجلس الوزراء المصري بتاريخ ه مايو 90 ام تم انشاء مكاتب سياحية في المدن التالية : جنيف - نيويورك مدريد - استكهولم - الكويت - لندن - بيروت - فرنكفورت، كما كان لها مسنتشارون وملحقون سياحيون في المدن التالية : باريس - سان فرانسيسكو - المكسيك - اثينا - شيكاغو، وبتاريخ أول أكتوبر ع 9 أندر صدر قرار السيد الوزير بإلغاء المكاتب ومراكز التمثيل الفنية بالخارج واحلال اعمال تللك المكاتب للثركات المصرية العامة للسياحة والفنادق بطرق الايجار على أسس تجاريـة الا أن هذا القرار لاقى العديد من السلبيات والعقبات نظراً لتعارض طبيعـة كل من الجنتين فبينما كانت تقوم هذه المكاتب بتلك الاعمال باعتبارها خدمات تؤديها بما يعود بـالنفع على الدولة عموماً تعتبرها الثركات مشروعاً تجارياً بقصد

إن الشق النسويقي لنشاط المكتب السياحي المصري يعتبر العمود الفقري لعمل المكتب السياحي والذى من أجله تم انشـاء المكتب مما يلزم لمن يقوم على إدارة هذه المكاتب ومن يعمل بها أيضاً أن يكون على خبرة عالية في الادارات المختلفة لوزارة السياحة وخصوصاً تللك الادارات التي ينصب نشاطها على التعامل مع الاسواق الخارجية مما سيتيح له معرفة أوجه التعاون والتتسيق بين تلك الادارات والمكاتب الخارجية وبدون هذه الخبرة العملية فإن الصلة التي تربط ادارات الوزارة بمكانبها الخارجية لن تكون محددة المعالم في ذهن مدير المكتب عند استلامه لمهام منصباه مما سيؤدى الى عدم تحقيق نتائج تتاسب الانفاق السنوي الكبير على تللك المكاتب.

\section{المهام الرئيسية للمكاتب الخارجية}

تقوم المكاتب الخارجية بدور فعال من أجل تدفق حركة السياحة الدولية لمصر بصفة عامة إلى جانب دراسة الأسواق السياحية

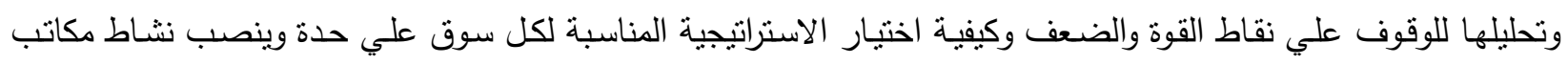
السياحة الخارجية علي الاتصال بالجماهير المخنلفة وذلك بهدف الإعلام والإقناع عن طريق جهود الإعلان والعلاقات العامة

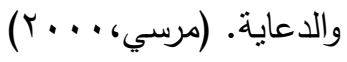

وفيما يلي بيان بأهم الأنشطة التي تقوم بها هذه المكاتب والتي يمكن استغلالها في تحسين الصورة الذهنية للسائح: • التعرف على أهم مصادر حركة السياحة في السوق السياحي بالخارج عن طريق دراسـة الأسواق السباحية من حيث

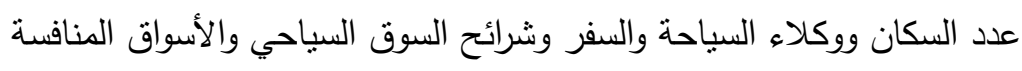
التعاون مع منظمي الرحلات الثاملة ووكلاء السياحة ومدهم بكل المواد الدعائية التي تساعدهم على جذب السائحين

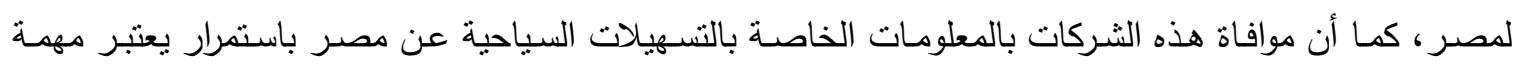

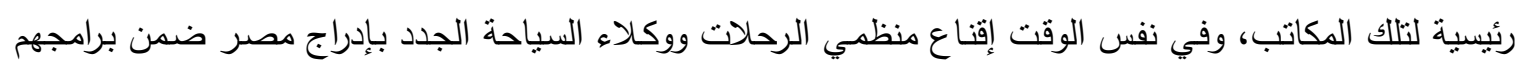

السباحية

الاهنمام بطرح أنماط متطورة من السياحة في السوق التي يعمل بها المكتب الاشتراك في المعارض السياحية التي تقام في المنطقة وذلك عن طريق جناح بعكس مقومات مصر السياحية 
تتظيم ورش عمل ونـدوات للاشـتراك مـع كبـري شـركات الطيـران ومنظمسي الـرحلات الثـاملة للتعريف بالمقومـات والتسهيلات السياحية المتوفرة في مصر ولمر

إلقاء المحاضرات والندوات السياحية التي تتضمن عرض الأفلام السياحية على تجمعات من الجماهير المستهدفة • إصدار المطبوعات السياحية التي يحتاج إليها السائحون إلى جانب النشرات السياحية إعطاء الاهتمام بنوافذ العرض ونشر عدد كبير من الملصقات الملفتة والجديدة إعداد تقارير ودراسات عن السوق السياحي يتضمن اقتراحات لانتهاج سياسة تسويقية فعالة

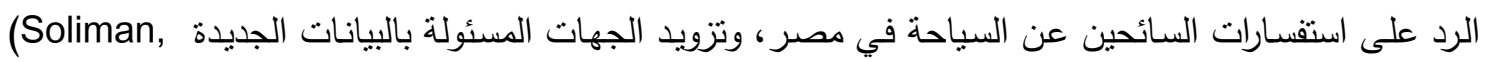

Wahba,2018)

\section{الصورة الذهنية للمقصد السياحي المصري}

ترنبط الصورة الذهنية الخاصة بالدول بالنمو الاقتصادي والتقنية والمكانة العالمية لها، ويعرف مصطلح الصورة الذهنية للدول على أنها الصورة أو السمعة أو الصورة النمطية التي يلحقها رجالا الأعمال والمستهلكون بمنتجات دول معينة، ويتم خلق هذه بـاته الصـورة عن طريق متغيرات مثل المنتجـات التي تمثنل الدولـة والسمات الوطنيـة والخلفيـة الاقتصـادية، والسياسية، والتاريخ،

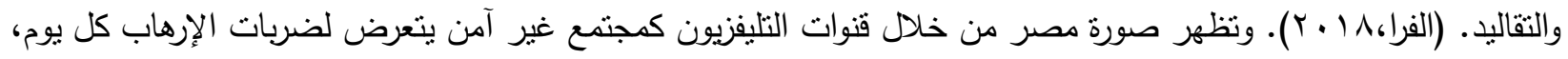

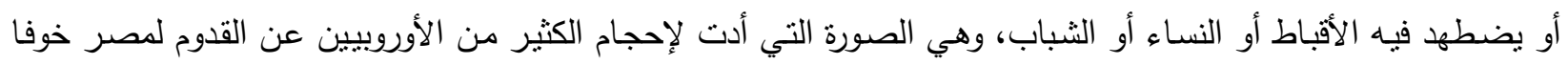

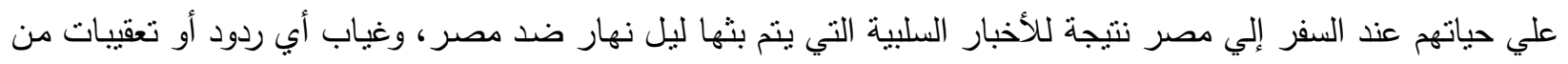
مصر عن كذب الادعاءات بأن شوارع مصر غير أمنة، فلا الهيئة العامة للاستعلامات ولا الملحقين التابعين لوزارات الإعلام والنقافة قاموا بدورهم في فضح هذه الادعاءات الكاذبة.(ندا، V · r) فتعتبر مراجعة الدولة للصورة الذهنية الحالية لدي جمهورها

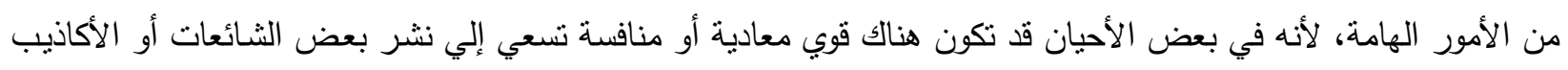

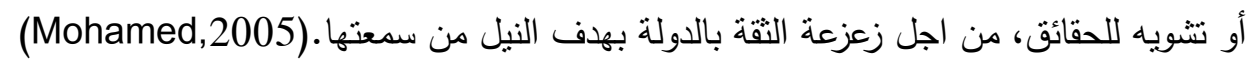

\section{الجهود المبذولة لتحسين الصورة الذهنية للمقصد السياحي المصري خلال الازمات}

أن هناك العديد من الجهود المبذولة علي المستويين الرسمي وغير الرسمي لتحسين صورة مصر الذهنية كمقصد سياحي عالمي خلال الازمات، فعلي المستوي الرسمي نم تقسيم مصر إلي أربع مقاصد سياحية ينت الترويج لكل منها علي حدة وهي

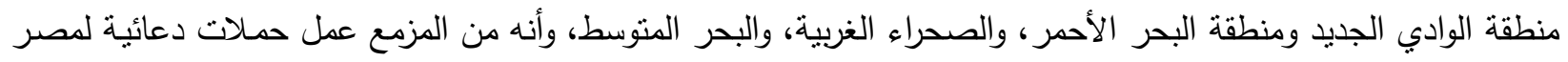
في السوق الإنجليزي والإيطالي، والتي ستعمل علي تحسين الصورة الذهنية لمصر كمقصد سياحي، وأن هيئة تتشيط السياحة تعمل علي فتح أسواق جديدة، وأنهم يقومون بنسويق اسم مصر كعلامة تجارية من خلال تسويق كل محافظة علي حدة من

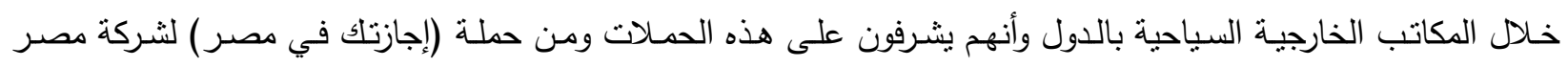

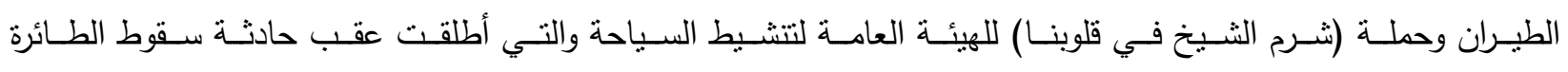

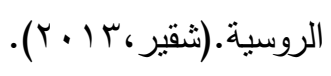




\section{توظيف الصورة الذهنية في الترويج للمقاصد السياحية بمصر}

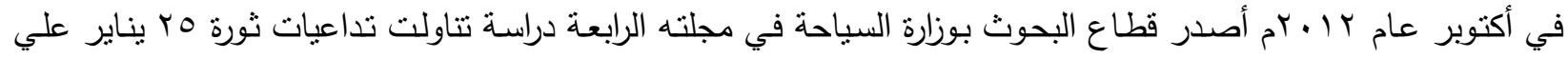
السياحة المصرية، وكيف بمكن التعامل معها من خلال التركيز علي الأسواق السياحية الدولية مثل روسيا وانجلترا وألمانيا

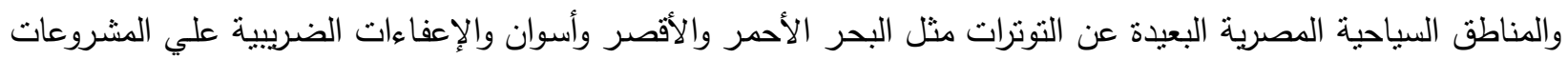

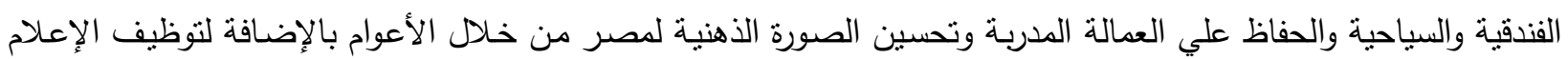
في حل المشكلات الاجتماعية والنقافية والسياسية والبيئية التي تعوق السياحة وأن تسنطلع السفارات والمكاتب السياحية بالخارج تتشيط الحركة السياحية في البلاد التي تمثل فيها عن طريق دراسة الإعلام المناسب الذي يؤثثر في السائحين ليعطي أفضل

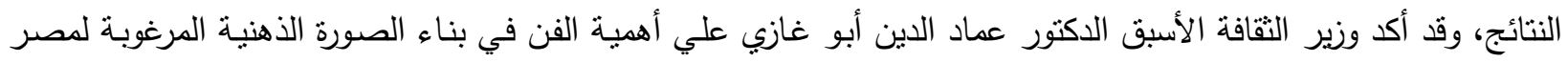

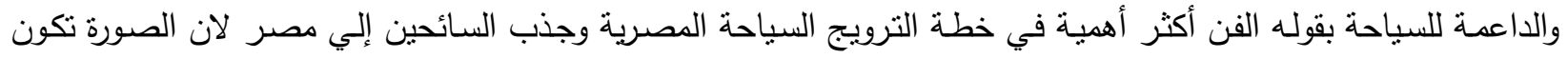

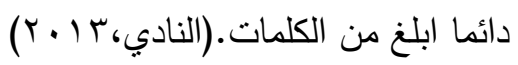

\section{الأزمات الااخلية والخارجية وآثارها على النشاط السياحي المصري}

يعتبر النثاط السياحي أحد أهم أعدة الاقتصاد المصري حيث يلعب دوراً قومياً كبيراً في مواجهة قضية البطالة حيث يعمل به

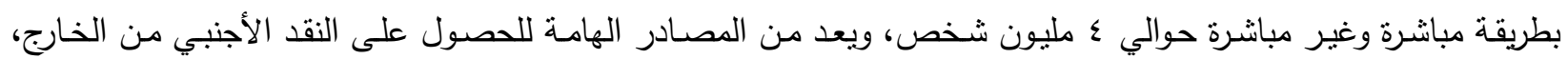

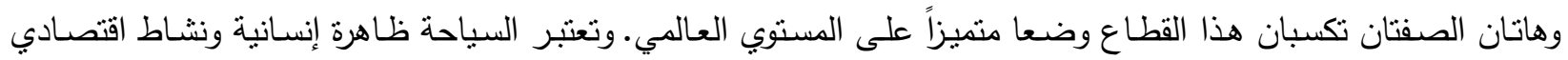

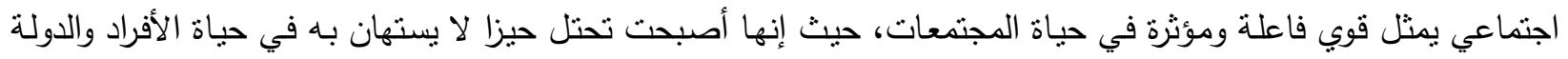

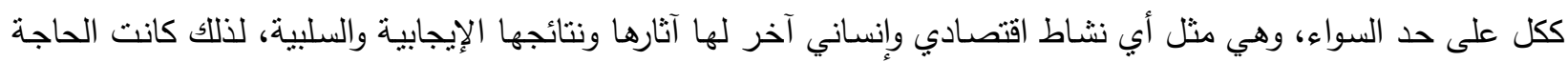

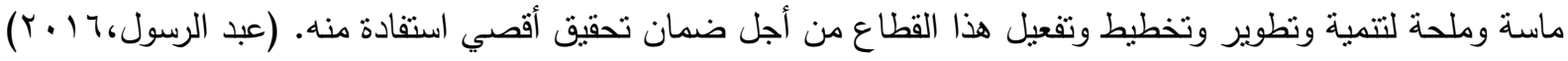
ولا شك أن السياحة لها أهمية خاصة مستمدة من نأثيرها على بنيان وأداء الاقتصاد الوطني، ويمكن النظر إليها على أنها

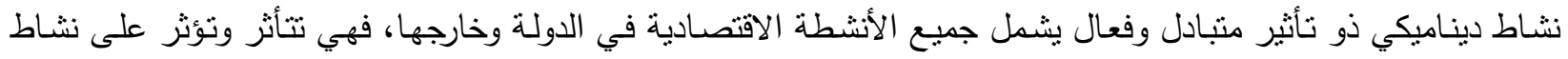

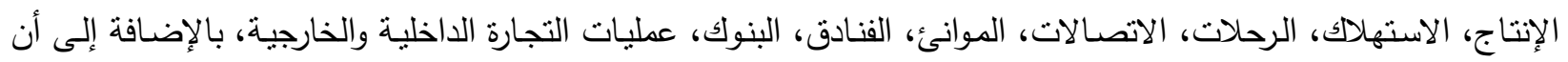

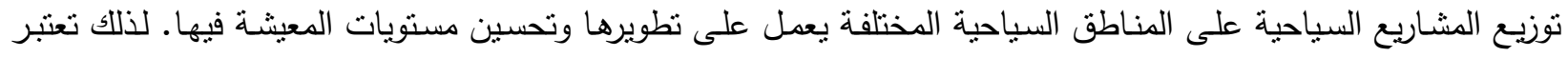
قضية التتمية السياحية عند الكثير من دول العالم، من القضايا المعاصرة، كونها تهدف إلى الإسهام في زيادة الدخل الفردي الحقيقي، بما تتضمنه من تتمية حضارية شاملة لكافة المقومات الطبيعية والإنسانية والمادية، ومن هنا تكون التتمية السياحية وسيلة للتنمية الاقتصادية.

فيجب توفر قاعدة للبيانات والمعلومات السياحية متكاملة وذلك لنجاح إدارة أزمة سياحية ويجب أن تتضمن هذه القاعدة كل ما يتعلق بالطلب السياحي مثل عدد السياح والليالي السياحية والإيرادات السياحية واتجاهات السياحة العالمية من كافة المناطق

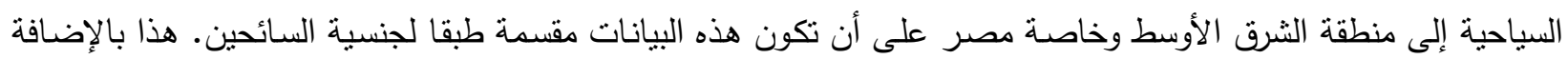

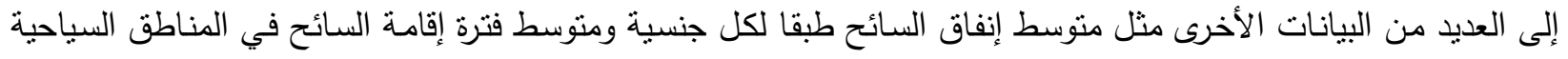
المختلفة إلى غير ذلك من البيانات الأخرى. وكذلك يجب أن تتضمن هذه القاعدة كل ما يتعلق بالعرض السباحي ووسائل

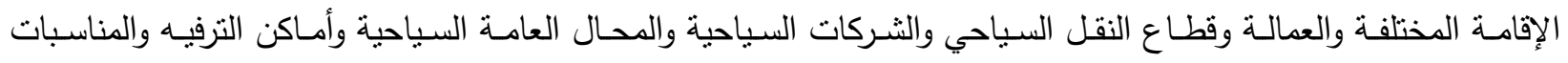


والمهرجانـات الخاصـة. هذا بالإضـافة إلي ضـرورة توفر البيانات والمعلومات الخاصـة بأثز القطاع السباحي علي الاقتصـاد القومي مثل الدخل السياحي الإجمالي والصـافي وأثزر هذا الدخل علي ميزان المدفوعات وراس المال المستثمر في القطاع السياحي والعمالة السياحية ومعدل النمو السياحي والأسعار السياحية مقارنة بالأسعار والعلاقة النتابكية بين القطاع السياحي والئي

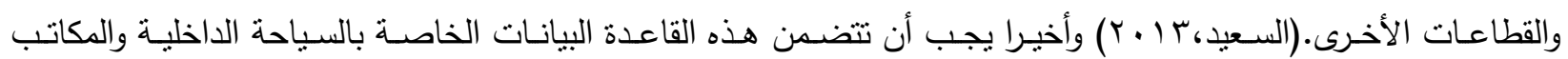
السياحية في الداخل والخارج والبيانات الخاصـة بالبيئة وأثزها علي القطاع السياحي، وكذلك دور وزارة الخارجية في الداخل

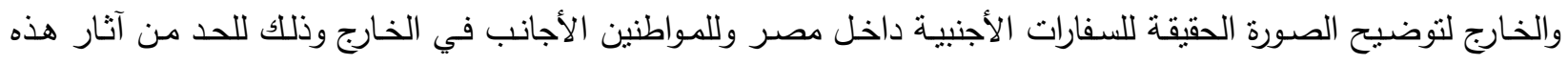
الأزمة، هذا بالإضافة إلي العديد من الإجراءات الأخرى التي تكمل هذه الخطوات.

وبـللك يمكن القول بأنـهـ مـن الضـروري وضـع سياسـة لإدارة الأزمات السياحية تلتنزم بها وزارة السياحة وغيرهـا مـن الأجهزة الحكومية وغير الحكومية وذلك حتى يمكن القضاء على أي أزمة قد يتعرض لها القطاع السياحي في المستقبل سواء كانت

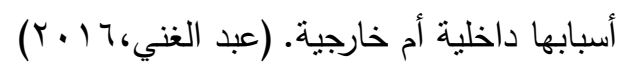
منهجية البحث

\section{مجتمع وعينة الاراسة}

تصنف هذه الدراسة ضمن الدراسات الوصفية، وقد نم إتباع منهجية تقليدية تعتمد على كلا الأسلوبين المكتبي والمبداني

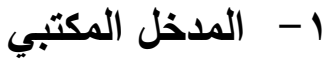

يعتمد هذا المدخل على التغطية الثاملة للأسس النظرية لموضوعات هيئة تنشيط السياحة بشكل عام والمكاتب الخارجية التابعة لها على وجه الخصوص. r - ب - المدخل الميداني

ويشمل استقصاء ميداني يستهدف عينة من السادة العاملين بالهيئة المصرية العامة للتشيط السياحي وموظفي وزارة السياحة

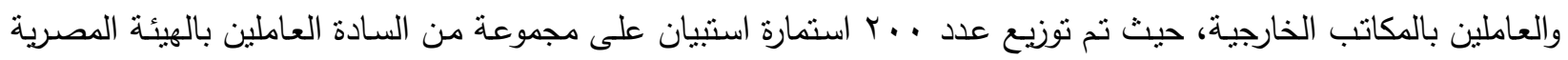
العامـة للتشتيط السياحي وموظفي وزارة السياحة والعاملين بالمكاتب الخارجية (بطريقة عشوائية)، وكان إجمالي الاستمارات

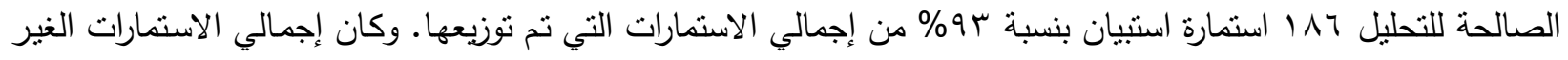
الصالحة للتحليل ع ا استمارة استبيان بنسبة >\% من إجمالي الاستبيانات التي تم توزيعها.

أداة البحث الميداني

اثنتمل الاستبيان علي ثناثة أقسام رئيسية، تضمن الأول منها: البيانات الثخصية لمجتمع البحث. بينما أشنمل القسم الثاني مجموعة من الاسئلة المتعلقة بموضوع الدراسة منل (ما هو الدور الرئيسي الذي يقوم به المكتب خارج مصر - إلي أي مدي يتم الترويج السياحي من جانب المكتب - ما المدة الزمنية التي يتم وضعها لتطبيق الخطة التسويقية لمصر - ما مدي فاعلية تطبيق تلك الخطط - هل يوجد خطط وإجراءات لتحسين الصورة الذهنية لمصر أمام السائحين - هل تساهم تلإك الممارسات والاجراءات في تحسين الصورة الذهنية لمصر). وأثنتمل القسم الثالث العبارات التوضيحية التي يتحقق من الاجابة عليها الهدف من الدراسة متمثلة في (طبيعة ومهام العمل بالمكاتب الخارجية - مؤهلات ومهارات موظفي المكاتب الخارجية - 
الامكانات المادية للمكاتب الخارجية - المعوقات التي نواجه المكاتب الخارجية - دور المكاتب الخارجية في تحسين الصورة الذهنية خلال الازمات) واعتمد الاستقصاء على مقياس ليكرت الخماسي بدرجات موافقة تتدرج من غير موافق بشدة حتى نواتى موافق بثدة.

النتائجج والمناقشة

جدول ا : معامل ألفا كرونباخ لقياس ثبات الاستقصاء.

\begin{tabular}{|c|c|}
\hline عدد العبارات & r. \\
\hline
\end{tabular}

يوضح الجدول (1) معامل ألفا كرونباخ المستخدم في قياس ثبات الاستقصاء، حيث توضـح النتائج أن قيمة ألفا بـر, •. وهي قيمة مقبولة حيث إن النسبة المقبولة بالنسبة للبحوث الإنسانية والاجتماعية •v\% فأكثر • وهو ما يشير إلى ثبات الاستقصاء وصلاحية الاعتماد عليه في الدراسة وثبات نتائجه إذا ما استخدم مرة أخري في نفس الظروف.

التحليل الوصفي لمحاور البحث

أولاً: البيانات الايموجرافية

جدول (r) تحليل البيانات الشخصية لمجتمع البحث

\begin{tabular}{|c|c|c|c|c|c|}
\hline \multirow{3}{*}{ الترتيب } & \multicolumn{2}{|c|}{ التكرارات والنسب المئوية } & \multirow{2}{*}{\multicolumn{3}{|c|}{ الـمتـغيـر }} \\
\hline & \multirow{2}{*}{$\frac{\%}{\text { or, r }}$} & \multirow{2}{*}{$\frac{ت}{99}$} & & & \\
\hline & & & ذكر & \multirow{2}{*}{ 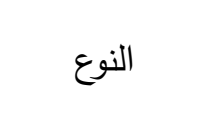 } & \multirow{2}{*}{-1} \\
\hline$r$ & $\leq 7, \wedge$ & $\Lambda V$ & أنتي & & \\
\hline \multicolumn{2}{|c|}{$\% 1 \ldots$} & 1117 & \multicolumn{3}{|c|}{ المجموع } \\
\hline 1 & $77, V$ & $1 Y \leq$ & جامعي & \multirow{3}{*}{ المؤهل الدراسي } & \\
\hline$r$ & r & 7. & دراسات عليا & & \\
\hline$r$ & 1,1 & r & أخري & & \\
\hline \multicolumn{2}{|c|}{$\% 1 \ldots$} & 1117 & \multicolumn{3}{|c|}{ المجموع } \\
\hline 1 & $\varepsilon \cdot, q$ & $V_{7}$ & أقل من هب & \multirow{3}{*}{ السن } & \multirow{3}{*}{ r } \\
\hline r & $0 ., 0$ & $9 \varepsilon$ & $0 .-\mu_{0}$ & & \\
\hline r & $\Lambda, 7$ & 17 & أكثر من .0 & & \\
\hline \multicolumn{2}{|c|}{$\% 1 \ldots$} & 1117 & \multicolumn{3}{|c|}{ المجموع } \\
\hline$\varepsilon$ & $1 \cdot, \wedge$ & $r$. & أقل من & \multirow{4}{*}{ سنوات الخبرة } & \multirow{4}{*}{$-\varepsilon$} \\
\hline r & $r \cdot, l$ & 07 & $1 .-0$ & & \\
\hline 1 & $\Gamma \wedge, \nu$ & $V Y$ & $10-1$. & & \\
\hline$r$ & $r \cdot, \Sigma$ & rᄉ & أكثر من 10 & & \\
\hline \multicolumn{2}{|c|}{$\% 1 \ldots$} & 1117 & \multicolumn{3}{|c|}{ المجموع } \\
\hline
\end{tabular}


يتضح من الجدول السابق (Y) الذي يوضح نوزيع المبحوثين وفقا لمتغير النوع، ان معظم أفراد عينة الدراسة عينة الدراسة هم

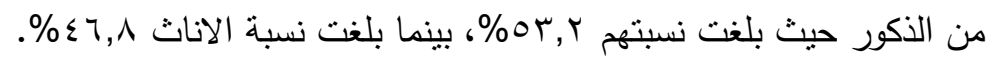

كما يوضح نوزيع افراد عينة الدراسة وفقا لمتغير المؤهل الدراسي، ان معظم افراد عينة الدراسة هم من المؤهلات الجامعية

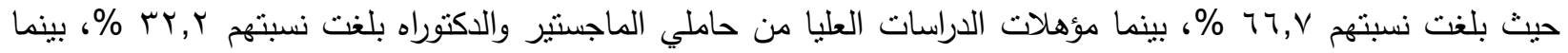

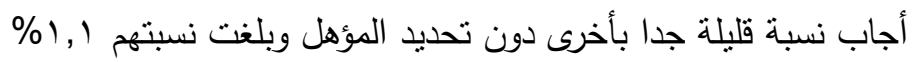

يتضح من الجدول السابق أيضا والذي يوضح توزيع افراد عينة الدراسة وفقا لمتغير السن، ان النسبة الأكبر من افراد عينة الدراسة بلغ عمرهم من هب الي لـ سنة حيث جاءت نسبتهم 0, .0٪\%، بينما بلغت نسبة من سنهم أقل من هب سنة المرتبة

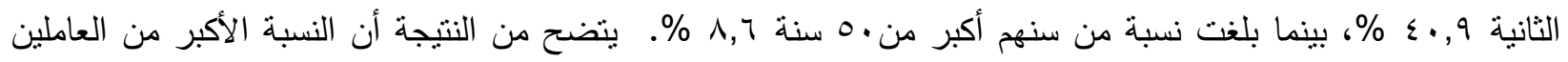
بالهيئة المصرية العامة للتنشيط السياحي وموظفي وزارة السياحة والعاملين بالمكاتب الخارجية من فئة الثباب. يتضح من الجدول السابق أيضا والذي يوضح نوزيع افراد عينة الدراسة وفقا لمتغير سنوات الخبرة، ان النسبة الأكبر من افراد

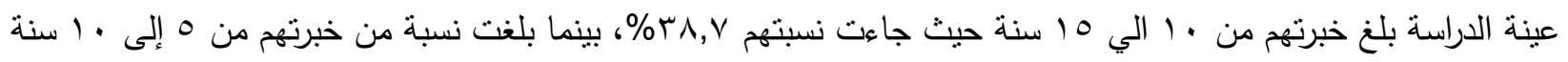

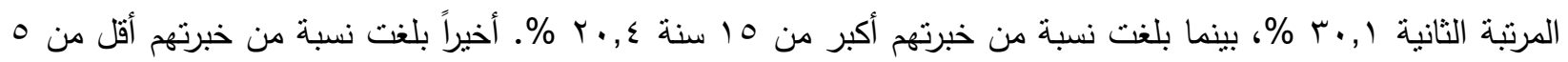

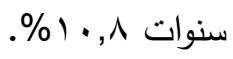

\section{ثانياً: تحليل محاور الدراسة}

جدول (ب) طبيعة ومهام العمل بالمكاتب الخارجية

\begin{tabular}{|c|c|c|c|c|c|c|c|c|c|}
\hline \multirow[b]{2}{*}{$\begin{array}{l}\text { 苂: } \\
\underline{E}\end{array}$} & \multicolumn{2}{|c|}{ المؤثرات الإحصائية } & \multicolumn{5}{|c|}{ درجة التكرار والنسبة المئوية } & \multirow{2}{*}{\multicolumn{2}{|c|}{ العبــارة }} \\
\hline & $\frac{5}{5}$ & $\stackrel{5}{E}$ & 1 & $r$ & $r$ & $\varepsilon$ & 0 & & \\
\hline \multirow[b]{2}{*}{ V } & \multirow{2}{*}{$\stackrel{i}{\sim}$} & \multirow{2}{*}{$\stackrel{N}{\sim}$} & 14 & 20 & 40 & 58 & 54 & 5) & \multirow{2}{*}{ تصني جمر المكاتب نشرات إخبارية توزع الجمـاهير وفي مقدمتهر } \\
\hline & & & $\dot{v i}$ & $\stackrel{0}{\infty}$ & $\frac{N}{i r}$ & $\underset{i}{\omega}$ & N & $\%$ & \\
\hline \multirow{2}{*}{0} & \multirow{2}{*}{$\overrightarrow{\dot{\omega}}$} & \multirow{2}{*}{$\begin{array}{l}\text { à } \\
\text { à }\end{array}$} & 22 & 40 & 18 & 64 & 42 & ك5 & \multirow{2}{*}{ 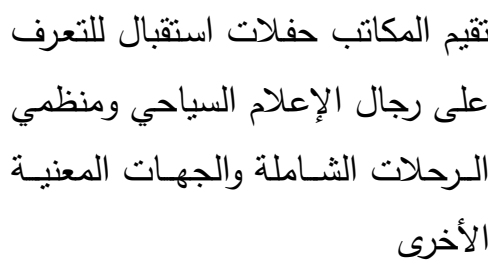 } \\
\hline & & & $\underset{\infty}{\varpi}$ & $\stackrel{N}{i}$ & $\stackrel{0}{v}$ & $\stackrel{\omega}{\stackrel{\oplus}{\Delta}}$ & $\begin{array}{l}N \\
\dot{a}\end{array}$ & $\%$ & \\
\hline \multirow[b]{2}{*}{1} & \multirow{2}{*}{$\begin{array}{l}0 \\
\dot{\Delta} \\
\dot{u}\end{array}$} & \multirow[b]{2}{*}{$\stackrel{+}{\dot{i}}$} & 8 & 81 & 5 & 0 & 0 & ك & \multirow{2}{*}{ 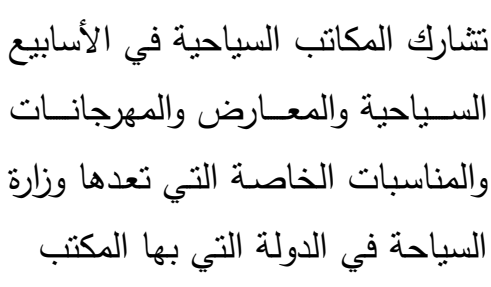 } \\
\hline & & & $\underset{\omega}{w}$ & $\begin{array}{l}\dot{\omega} \\
\dot{a}\end{array}$ & $\stackrel{N}{a}$ & 0 & 0 & $\%$ & \\
\hline
\end{tabular}




\begin{tabular}{|c|c|c|c|c|c|c|c|c|c|}
\hline \multirow[b]{2}{*}{ 苂: } & \multicolumn{2}{|c|}{ المؤثرات الإحصائية } & \multicolumn{5}{|c|}{ درجة التكرار والنسبة المئوية } & \multirow{2}{*}{\multicolumn{2}{|c|}{ العبــارة }} \\
\hline & $\frac{5}{5}$ & $\stackrel{5}{E}$ & 1 & r & $r$ & $\varepsilon$ & 0 & & \\
\hline \multirow[b]{2}{*}{ r } & \multirow{2}{*}{$\stackrel{\overrightarrow{+}}{+\infty}$} & \multirow[b]{2}{*}{$\dot{\omega}$} & 80 & 26 & 28 & 32 & 20 & ك & \multirow{2}{*}{ تمـــد المتعــاملين معهــا بالنشــرات } \\
\hline & & & $\stackrel{\oplus}{\omega}$ & $\vec{\perp}$ & $\bar{\varphi}$ & $\stackrel{\nabla}{i}$ & $\underset{\infty}{\infty}$ & $\%$ & \\
\hline \multirow[b]{2}{*}{$\wedge$} & \multirow[b]{2}{*}{$\frac{\vec{i}}{a}$} & \multirow[b]{2}{*}{$\stackrel{\sim}{\omega}$} & 8 & 36 & 22 & 64 & 56 & ك & \multirow[b]{2}{*}{ ثقوم المكاتب بإرسال القوافل السياحية } \\
\hline & & & $\stackrel{+}{\dot{\omega}}$ & $\begin{array}{l}\vec{b} \\
\dot{\phi}\end{array}$ & $\underset{\infty}{\varpi}$ & $\underset{⿱ 亠}{\stackrel{\omega}{\perp}}$ & $\stackrel{\omega}{\stackrel{\omega}{\circ}}$ & $\%$ & \\
\hline \multirow[b]{2}{*}{ r } & \multirow[b]{2}{*}{$\dot{\vec{\omega}}_{\dot{v}}$} & \multirow[b]{2}{*}{$\dot{\omega}$} & 68 & 46 & 42 & 22 & 8 & ك & \multirow{2}{*}{ حلحـد الاستراتيجية الأســواق السـباحية واختيــار } \\
\hline & & & $\begin{array}{l}\omega \\
\dot{a} \\
\dot{a}\end{array}$ & $\stackrel{N}{+}$ & $\begin{array}{l}N \\
\dot{a}\end{array}$ & $\varpi_{\infty}$ & $\underset{i}{i}$ & $\%$ & \\
\hline \multirow[b]{2}{*}{7} & \multirow[b]{2}{*}{$\stackrel{一}{N}$} & \multirow[b]{2}{*}{$\stackrel{N}{\stackrel{N}{u}}$} & 14 & 22 & 38 & 72 & 40 & 5 & \multirow{2}{*}{ يُعــرح أنـــاط متطـورة مـن السـياحة } \\
\hline & & & $v_{i}$ & 戸 & $\stackrel{N}{0}$ & $\begin{array}{l}\omega \\
\dot{\omega}\end{array}$ & $\frac{N}{i r}$ & $\%$ & \\
\hline \multirow[b]{2}{*}{$\varepsilon$} & \multirow[b]{2}{*}{$\dot{\tilde{v}}$} & \multirow[b]{2}{*}{$\stackrel{\omega}{\omega}$} & 30 & 46 & 50 & 38 & 22 & ك & \multirow{2}{*}{ 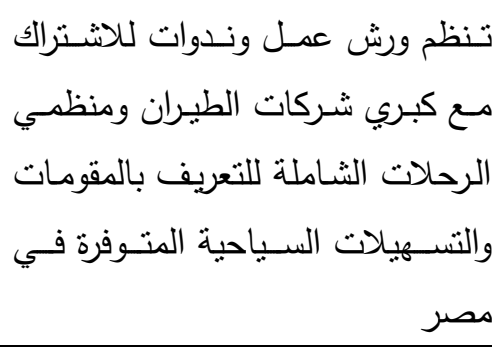 } \\
\hline & & & $\stackrel{\vec{a}}{\dot{1}}$ & $\stackrel{N}{+}$ & $\underset{\sigma}{0}$ & $\stackrel{0}{\circ}$ & $\underset{\infty}{\varpi}$ & $\%$ & \\
\hline- & $\dot{\bar{\sigma}}$ & $\dot{\omega}_{0}^{\omega}$ & \multicolumn{7}{|c|}{ الــــــوســط الـــــــــــــــام } \\
\hline
\end{tabular}

|ك= تكرارات

يتضح أن اجابات أفراد عينة الدراسة محايدة على عبارات المحور الأول (طبيعة ومهام العمل بالمكاتب الخارجية) بمنوسط

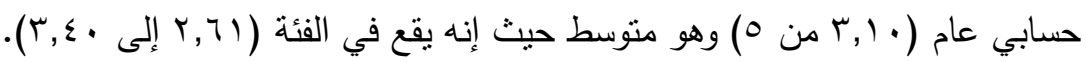

يتضح من النتائج أن أفراد عينة الدراسة يوافقوا بشدة على عبارة واحدة من عبارات المحور الأول (طبيعة ومهام العمل بالمكاتب الخارجية)، وهي كما يلي: 
• عبارة "تثارك المكاتب السياحية في الأسابيع السياحية والمعارض والمهرجانات والمناسبات الخاصة التي تعدها وزارة

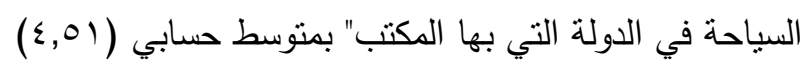

يتضح من النتائج أن أفراد عينة الدراسة يوافقوا على عبارتين من عبارات المحور الأول (طبيعة ومهام العمل بالمكاتب

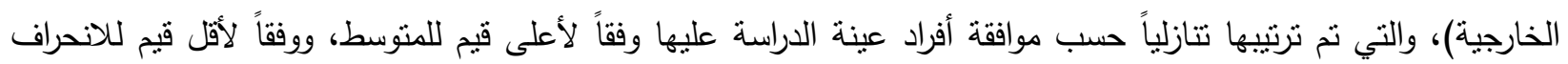

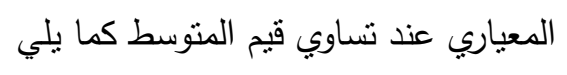

• عبارة "تحدد الأسواق السياحية واختيار الاستراتيجية المناسبة لكل سوق على حدة" بمتوسط حسابي (r,YVV)

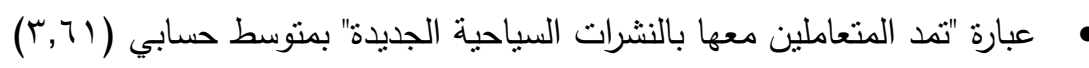

يتضح من الننائج أن أفراد عينة الدراسة إجاباتهم كانت محايدة على عبارتين عبارات الدحور الأول (طبيعة ومهام العمل

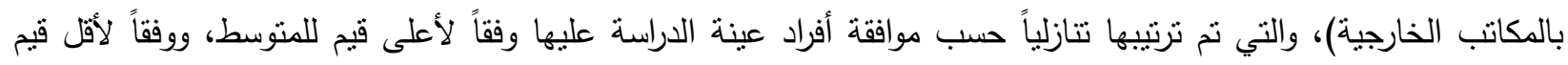

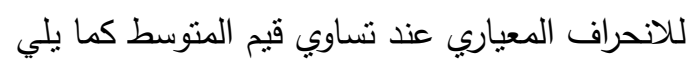

عبارة "تظظ ورش عمل وندوات للاثشتراك مع كبري شركات الطيران ومنظمي الرحلات الثشاملة للتعريف بالمقومات

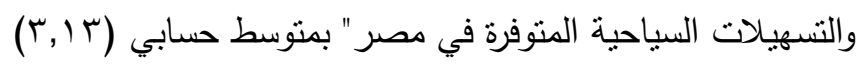

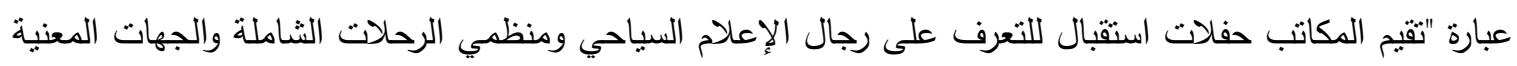

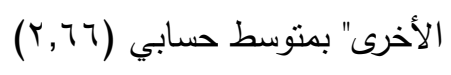

بتضح من النتائج أن أفراد عينة الدراسة لم يوافقوا على ثلاث عبارات من عبارات المحور الأول (طبيعة ومهام العمل بالمكاتب التبات

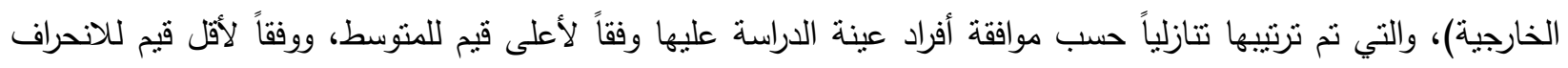

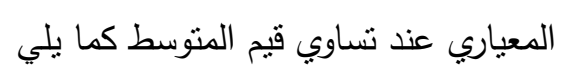

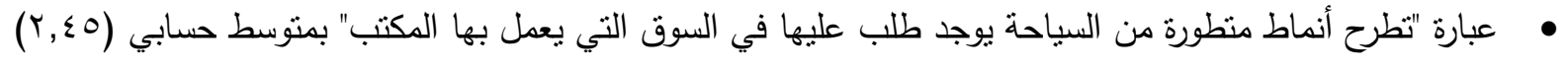

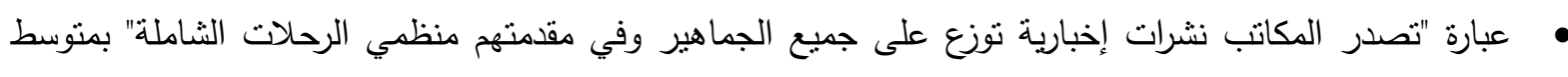

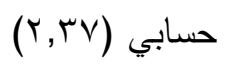

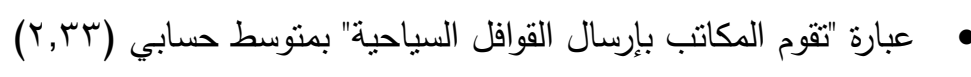

اتضح من الدراسة ان من أكثر الانثطة التي تثوم بها المكاتب الخارجية أنها تشارك المكاتب السياحية في الأسابيع السباحية

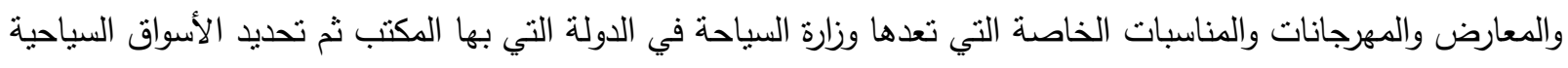

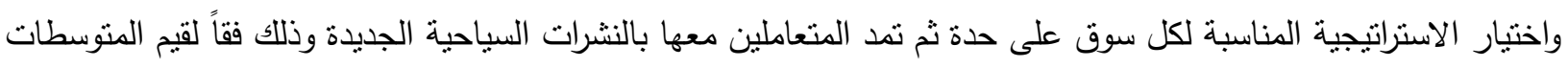
كما انه لم يتم التعليق على قيم الانحراف المعياري لأن قيمه تعبر عن تنتئت الاستجابات. 
جدول ( ) مؤهلات ومهارات موظفي المكاتب الخارجية

\begin{tabular}{|c|c|c|c|c|c|c|c|c|c|}
\hline \multirow[b]{2}{*}{ 覧 } & \multicolumn{2}{|c|}{ المؤشرات الإحصائية } & \multicolumn{5}{|c|}{ درجة التكرار والنسبة المئوية } & \multirow{2}{*}{\multicolumn{2}{|c|}{ العبــارة }} \\
\hline & 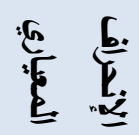 & $\stackrel{5}{E}$ & 1 & 2 & 3 & 4 & 5 & & \\
\hline \multirow{2}{*}{7} & \multirow{2}{*}{$\begin{array}{l}\stackrel{1}{t} \\
\dot{\theta}\end{array}$} & \multirow{2}{*}{$\overrightarrow{\dot{\infty}}$} & 0 & 0 & 17 & 55 & $\vec{\nabla}$ & ك & \multirow{2}{*}{ 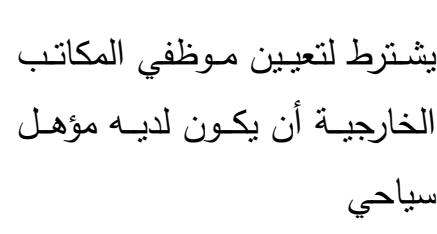 } \\
\hline & & & 0 & 0 & $\stackrel{?}{i}$ & $\begin{array}{l}\text { No } \\
\text { a }\end{array}$ & $\stackrel{a}{i}$ & $\%$ & \\
\hline \multirow[b]{2}{*}{1} & \multirow{2}{*}{$\overrightarrow{\mathrm{N}}$} & \multirow{2}{*}{$\underset{⿱ 亠 凶}{\dot{\infty}}$} & 30 & 66 & 32 & 42 & 16 & ك & \multirow{2}{*}{ الدهارات والمؤهلات الكافية المكاتب الدارجيـة } \\
\hline & & & $\vec{\sigma}$ & $\ddot{w}_{u}^{w}$ & $\underset{i}{\vec{i}}$ & $\begin{array}{l}N \\
\stackrel{N}{a}\end{array}$ & $\begin{array}{l}\infty \\
\dot{\sigma}\end{array}$ & $\%$ & \\
\hline \multirow[b]{2}{*}{$\varepsilon$} & \multirow[b]{2}{*}{$\overrightarrow{\tilde{w}}$} & \multirow[b]{2}{*}{$\stackrel{\sim}{\dot{\omega}}$} & 12 & 24 & 36 & 52 & 62 & s & \multirow{2}{*}{ 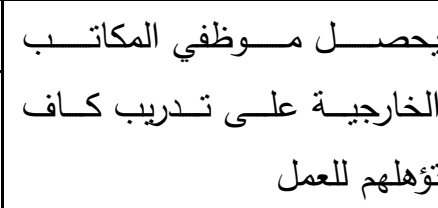 } \\
\hline & & & iे & $\stackrel{N}{\sigma}$ & $\stackrel{\varpi}{\square}$ & $N$ & $\underset{\omega}{\omega}$ & $\%$ & \\
\hline \multirow[b]{2}{*}{$r$} & \multirow{2}{*}{$\begin{array}{l}\dot{0} \\
\dot{0}\end{array}$} & \multirow{2}{*}{$\stackrel{N}{\infty}$} & 2 & 58 & 52 & 54 & 20 & ك5 & \multirow{2}{*}{ 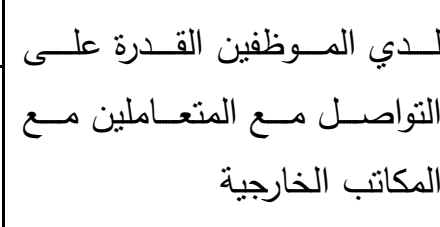 } \\
\hline & & & 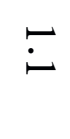 & $\underset{i}{\omega}$ & $\underset{\infty}{N}$ & $\mathbb{0}$ & $\underset{\infty}{\infty}$ & $\%$ & \\
\hline \multirow[b]{2}{*}{5} & \multirow[b]{2}{*}{$\stackrel{\circ}{\underset{j}{w}}$} & \multirow[b]{2}{*}{$\stackrel{N}{\dot{\theta}}$} & 0 & 12 & 37 & 89 & 48 & ك & \multirow{2}{*}{ 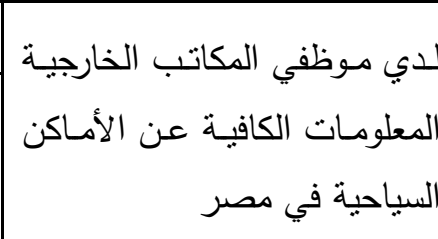 } \\
\hline & & & 0 & 8 & ర్ర & $\underset{\hat{\sigma}}{t}$ & $\begin{array}{l}\text { un } \\
\infty\end{array}$ & $\%$ & \\
\hline \multirow[b]{2}{*}{$r$} & \multirow[b]{2}{*}{ 灾 } & \multirow[b]{2}{*}{ 汿 } & 8 & 54 & 60 & 44 & 20 & ك & \multirow{2}{*}{ 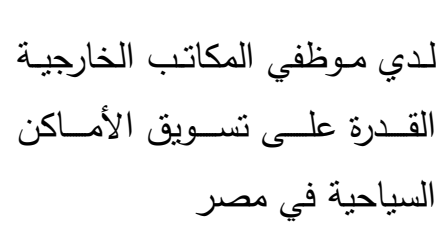 } \\
\hline & & & $\dot{\omega}$ & N & 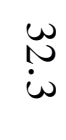 & $\stackrel{N}{\dot{\nu}}$ & $\underset{\infty}{0}$ & $\%$ & \\
\hline- & $\dot{0}$ & $\begin{array}{l}\stackrel{N}{a} \\
\dot{D}\end{array}$ & \multicolumn{7}{|c|}{ 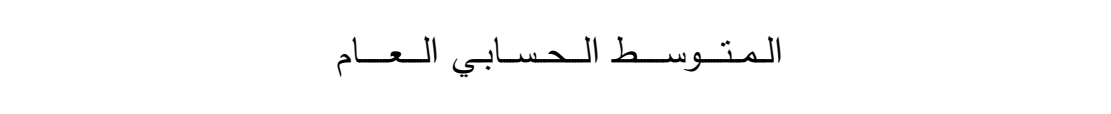 } \\
\hline
\end{tabular}

$$
\text { تكرارات }
$$

يتضح أن اجابات أفراد عينة الدراسة ليست موافقة على عبارات الدحور الثاني (مؤهلات ومهارات موظفي المكاتب الخارجية)

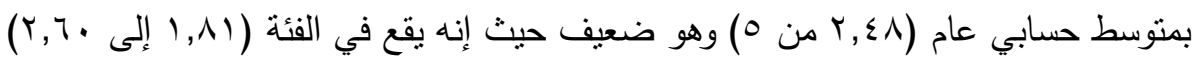


يتضح من النتائج أن أفراد عينة الدراسة إجاباتهم كانت محايدة على ثلاث عبارات من عبارات المحور الثاني (مؤهلات

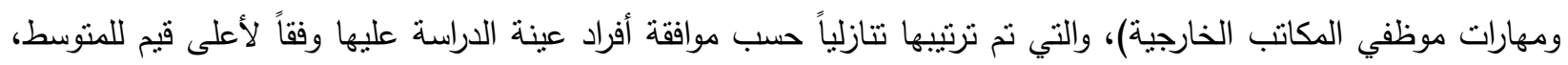

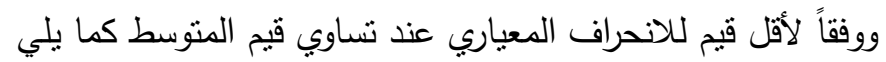

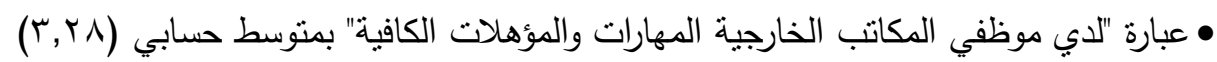

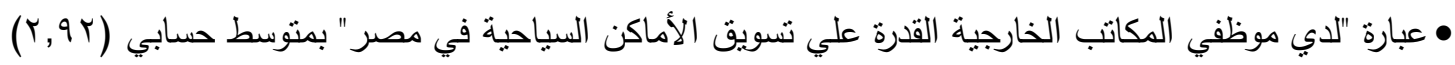

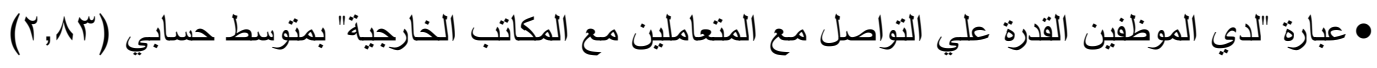
يتضح من النتائج أن أفراد عينة الدراسة لم يوافقوا على عبارتين من عبارات المحور الثاني (مؤهلات ومهارات موظفي المكاتب الخارجية)، كما يلي

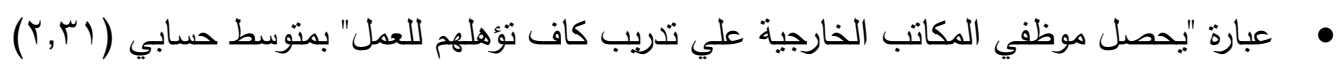

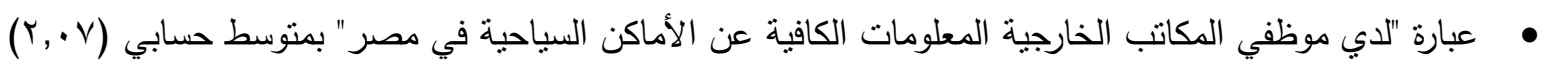
يتضح من النتائج أن أفراد عينة الدراسة لم يوافقوا بشدة على عبارة من عبارات المحور الثاني (مؤهلات ومهارات موظفي المكانب الخارجية)، كما يلي ملي

• عبارة "يشترط لتعيين موظفي المكاتب الخارجية علي أن يكون لديه مؤهل سياحي" بمتوسط حسابي (^乞 , ا ) اتضح من الدراسة ان من أكثر المؤهلات والمهارات التي لا يتميز بها موظفي المكاتب الخارجية هي عدم حصول موظفي المكاتب الخارجية علي تدريب كاف تؤهلهم للعمل ثم ليس لديهم المعلومات الكافية عن الأماكن السياحية في مصر ثم لا يشترط لتعيينهم أن يكون لديهم مؤهل سياحي وذلك فقاً لقيم المتوسطات كما انه لم ينم التعليق على قيم الانحراف المعياري لأن قيمه تعبر عن نشتت الاستجابات.

جدول (0) المعوقات التي تواجه المكاتب الخارجية

\begin{tabular}{|c|c|c|c|c|c|c|c|c|c|}
\hline \multirow{2}{*}{ 证: } & \multicolumn{2}{|c|}{ المؤشرات الإحصائية } & \multicolumn{5}{|c|}{ درجة التكرار والنسبة المئوية } & \multirow{2}{*}{\multicolumn{2}{|c|}{ العبـــارة }} \\
\hline & {$\left[\begin{array}{cc}E \\
E\end{array}\right.$} & $\underline{E}$ & 1 & 2 & 3 & 4 & 5 & & \\
\hline \multirow[b]{2}{*}{0} & \multirow{2}{*}{$\stackrel{\vec{i}}{+}$} & \multirow[b]{2}{*}{$\dot{\omega}$} & 52 & 66 & 34 & 16 & 18 & 5) & \multirow{2}{*}{ داخل البيروقراطيــــة فـــي أداء العـــلـ } \\
\hline & & & $\infty$ & $\begin{array}{l}u_{u} \\
\dot{u}\end{array}$ & $\begin{array}{l}\infty \\
\dot{\omega}\end{array}$ & $\begin{array}{l}\infty \\
\dot{a}\end{array}$ & $\begin{array}{l}0 \\
ن\end{array}$ & $\%$ & \\
\hline \multirow[b]{2}{*}{7} & \multirow{2}{*}{$\dot{\bar{N}}$} & \multirow[b]{2}{*}{$\stackrel{\omega}{\dot{c}}$} & 36 & 60 & 50 & 28 & 12 & 5) & \multirow[b]{2}{*}{ عدم وجود كفاءات مهنية متميزة } \\
\hline & & & $\begin{array}{l}\overrightarrow{0} \\
\dot{D}\end{array}$ & $\underset{⿱ \omega}{\omega}$ & $\begin{array}{l}\tilde{\sigma} \\
\dot{\sigma}\end{array}$ & $\dot{\bar{u}}$ & ir & $\%$ & \\
\hline
\end{tabular}




\begin{tabular}{|c|c|c|c|c|c|c|c|c|c|}
\hline \multirow[b]{2}{*}{ 苂: } & \multicolumn{2}{|c|}{ المؤشرات الإحصائية } & \multicolumn{5}{|c|}{ درجة التكرار والنسبة المئوية } & \multirow{2}{*}{\multicolumn{2}{|c|}{ العبــارة }} \\
\hline & $\sum_{5}^{5}$ & $\stackrel{q}{E}$ & 1 & 2 & 3 & 4 & 5 & & \\
\hline \multirow[b]{2}{*}{$\varepsilon$} & \multirow[b]{2}{*}{$\underset{\infty}{+}$} & \multirow[b]{2}{*}{$\stackrel{\omega}{N}$} & 56 & 50 & 58 & 16 & 6 & ك5 & \multirow{2}{*}{ 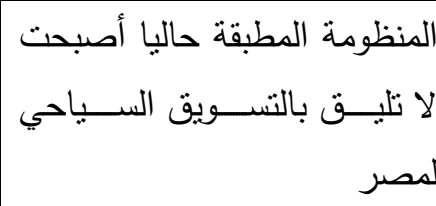 } \\
\hline & & & $\stackrel{\omega}{\stackrel{\varphi}{\ominus}}$ & $\underset{\sigma}{n}$ & $\stackrel{\omega}{\omega}$ & $\begin{array}{l}\infty \\
\dot{a}\end{array}$ & & $\%$ & \\
\hline \multirow[b]{2}{*}{ 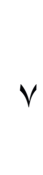 } & \multirow{2}{*}{$\vec{i}$} & \multirow[b]{2}{*}{$\dot{w}_{u}^{w}$} & 42 & 48 & 52 & 22 & 22 & ك & \multirow{2}{*}{ وجود لوائح وقوانين مكبلـة لأداء } \\
\hline & & & $\begin{array}{l}N \\
\mathfrak{a}\end{array}$ & $\begin{array}{c}N \\
\dot{\infty}\end{array}$ & $\infty$ & $\underset{\infty}{\varpi}$ & $\underset{\infty}{\varpi}$ & $\%$ & \\
\hline \multirow[b]{2}{*}{ r } & \multirow{2}{*}{$\stackrel{\oplus}{\dot{\jmath}}$} & \multirow[b]{2}{*}{ ú } & 84 & 44 & 32 & 16 & 10 & ك & \multirow{2}{*}{ كافة الدول التي تشتهـدفها مكاتب كافيـة تشــل } \\
\hline & & & $\begin{array}{l}\dot{c} \\
\dot{i}\end{array}$ & $\stackrel{\sim}{\omega}$ & $\vec{v}$ & $\begin{array}{l}\infty \\
\dot{a}\end{array}$ & $\ddot{\dot{D}}$ & $\%$ & \\
\hline \multirow[b]{2}{*}{ r } & \multirow[b]{2}{*}{$\begin{array}{l}\dot{0} \\
\dot{a} \\
\frac{1}{\infty}\end{array}$} & \multirow[b]{2}{*}{$\stackrel{+}{\dot{\theta}}$} & 59 & 84 & 40 & 3 & 0 & ك5 & \multirow{2}{*}{ 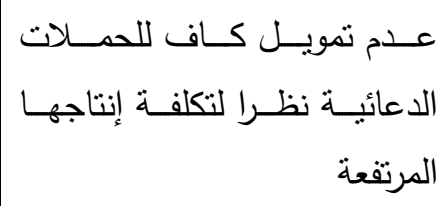 } \\
\hline & & & $\stackrel{\omega}{\dot{\omega}}$ & 它 & in & $\dot{a}$ & 0 & $\%$ & \\
\hline \multirow[b]{2}{*}{1} & \multirow{2}{*}{$\begin{array}{l}0 \\
\dot{u}\end{array}$} & \multirow{2}{*}{$\stackrel{+}{\dot{w}}$} & 62 & $\overrightarrow{0}$ & 19 & 0 & 0 & ك5 & \multirow{2}{*}{ 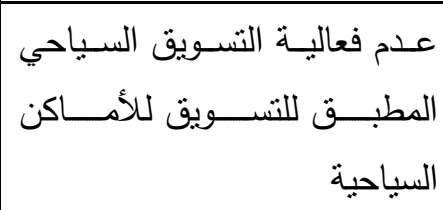 } \\
\hline & & & $\underset{\omega}{\omega}$ & $\begin{array}{l}\text { ù } \\
\text { ir }\end{array}$ & $\begin{array}{l}\overrightarrow{0} \\
\dot{1}\end{array}$ & 0 & 0 & $\%$ & \\
\hline \multirow[b]{2}{*}{$\wedge$} & \multirow[b]{2}{*}{$\underset{\infty}{\grave{\alpha}}$} & \multirow[b]{2}{*}{$\stackrel{N}{\dot{N}}$} & 12 & 28 & 48 & 36 & 62 & ك & \multirow{2}{*}{ 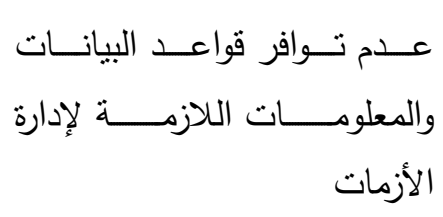 } \\
\hline & & & $\stackrel{a}{\text { ir }}$ & 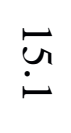 & $\underset{\infty}{\sim}$ & $\overrightarrow{0}$ & $\underset{\omega}{\omega}$ & $\%$ & \\
\hline- & $\dot{\dot{y}}$ & $\begin{array}{l}\omega \\
\dot{g}\end{array}$ & \multicolumn{7}{|c|}{ 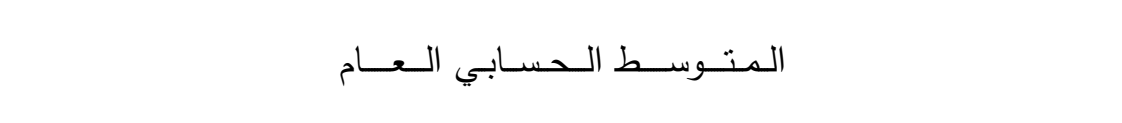 } \\
\hline
\end{tabular}

$$
\text { "ك = تكرارات* }
$$

يتضح أن اجابات أفراد عينة الدراسة موافقة على عبارات المحور الثالث (المعوقات التي تواجه المكاتب الخارجية) بمتوسط

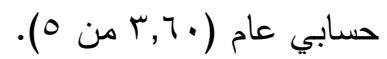
يتضح من النتائج أن أفراد عينة الدراسة قد وافقوا بشدة على عبارة واحدة من عبارات المحور الثالث (المعوقات التي نواجه

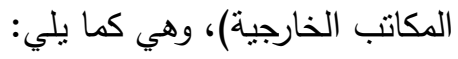
• عبارة "عدم فعالية التسويق السياحي المطبق للتسويق للأماكن السياحية " بمتوسط حسابي (r, ع ؛ 
يتضح من النتائج أن أفراد عينة الدراسة يوافقوا على أغلب عبارات المحور الثالث (المعوقات التي تواجه المكاتب الخارجية)، كما يلي:

• عبارة "عدم تمويل كاف للحملات الدعائية نظرا لتكلفة إنتاجها المرتفعة" بمنوسط حسابي (v •, ع)

• عبارة "عدم وجود مكاتب كافية تشمل كافة الدول التي تستهدفها مصر" بمنوسط حسابي (؟0, • عبارة " المنظومة المطبقة حاليا أصبحت لا تليق بالتسويق السياحي لمصر" بمنوسط حسابي (r,VY)

عبارة " البيروقراطية في أداء العمل داخل الهيئة" بمنوسط حسابي (T,T)

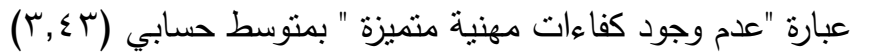

يتضح من النتائج أن أفراد عينة الدراسة إجاباتهم كانت محايدة على عبارة واحدة من عبارات المحور الثالث (المعوقات التي تواجه المكاتب الخارجية)، كما يلي

• عبارة وجود لوائح وقوانين مكبلة لأداء المكاتب لمهامها " بمنوسط حسابي (0, ب)، وهو متوسط حسابي متوسط لأنه واقع

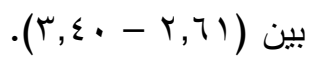

يتضح من النتائج أن أفراد عينة الدراسة لم يوافقوا على عبارة واحدة من عبارات المحور الثالث (المعوقات الني تواجه المكاتب الخارجية)، كما يلي من ليج • عبارة "عدم توافر قواعد البيانات والمعلومات اللازمة لإدارة الأزمات" بمتوسط حسابي (Y (Y, )، وهو متوسط ضعيف حيث

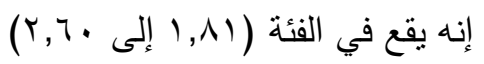

اتضح من الدراسة ان من اكثر المعوقات التي تواجه المكاتب الخارجية هي عدم فعالية التسويق السياحي المطبق للنسويق للأماكن السياحية ثم عدم تمويل كاف للحملات الدعائية نظرا لتكلفة إنتاجها المرتفعة ثم عدم وجود مكاتب كافية تشمل كافة الدول التي تستهدفها مصر ثم المنظومة المطبقة حاليا أصبحت لا تليق بالتسويق السياحي لمصر ثم البيروقراطية في أداء العمل داخل الهيئة ثم عدم وجود كفاءات مهنية متميزة وذلك فقاً لقيم المتوسطات كما انه لم يتم التعليق على قيم الانحراف المعياري لأن قيمه تعبر عن تشتت الاستجابات.

\begin{tabular}{|c|c|c|c|c|c|c|c|c|c|}
\hline \multirow[b]{2}{*}{ 证: } & \multicolumn{2}{|c|}{ المؤشرات الإحصائية } & \multicolumn{5}{|c|}{ درجة التكرار والنسبة المئوية } & \multirow{2}{*}{\multicolumn{2}{|c|}{ العبـــارة }} \\
\hline & {$\left[\begin{array}{c}E \\
E \\
E\end{array}\right.$} & $E$ & 1 & 2 & 3 & 4 & 5 & & \\
\hline \multirow[b]{2}{*}{7} & \multirow{2}{*}{$\stackrel{i}{\underline{v}}$} & \multirow{2}{*}{$\ddot{\omega}$} & 24 & 42 & 56 & 40 & 24 & 5 & \multirow{2}{*}{ تمتلـ مصـر صـورة ذهنيـة جيـدة } \\
\hline & & & $\stackrel{\sim}{6}$ & $\begin{array}{l}N \\
\dot{\sigma}\end{array}$ & $\stackrel{\omega}{0}$ & $\stackrel{N}{\text { ir }}$ & $\stackrel{\sim}{6}$ & $\%$ & \\
\hline
\end{tabular}

جدول (ج) دور المكاتب الخارجية في تحسين الصورة الذهنية خلال الازمات 


\begin{tabular}{|c|c|c|c|c|c|c|c|c|c|}
\hline \multirow[b]{2}{*}{ E: } & \multicolumn{2}{|c|}{ المؤشرات الإحصائية } & \multicolumn{5}{|c|}{ درجة التكرار والنسبة المئوية } & \multirow{2}{*}{\multicolumn{2}{|c|}{ العبــارة }} \\
\hline & $\underline{E}$ & E & 1 & 2 & 3 & 4 & 5 & & \\
\hline \multirow[b]{2}{*}{$r$} & \multirow[b]{2}{*}{$\dot{\bar{\varphi}}$} & \multirow[b]{2}{*}{$\begin{array}{l}\infty \\
\infty\end{array}$} & 74 & 44 & 52 & 4 & 12 & ك & \multirow{2}{*}{ لظفهـر صــورة مصـر مـن خــلاد } \\
\hline & & & $\begin{array}{l}\omega \\
\dot{\infty} \\
\dot{\infty}\end{array}$ & $\underset{\omega}{\sim}$ & $\infty$ & $\stackrel{N}{i}$ & ir & $\%$ & \\
\hline \multirow[b]{2}{*}{ r } & \multirow[b]{2}{*}{ 官 } & \multirow[b]{2}{*}{$\dot{\infty}_{\infty}^{\infty}$} & 36 & 54 & 66 & 24 & 6 & ك & \multirow{2}{*}{ توجد ردود أو تعقيبات من المكاتب } \\
\hline & & & $\underset{\square}{\oplus}$ & N & ü & $\stackrel{i}{i}$ & & $\%$ & \\
\hline \multirow{2}{*}{1} & \multirow{2}{*}{$\stackrel{\circ}{\dot{0}}$} & \multirow{2}{*}{$\stackrel{+}{6}$} & $\vec{a}$ & 17 & 0 & 0 & 0 & ك & \multirow{2}{*}{ تالثـروج المكاتـب للامــاكن السـياحية } \\
\hline & & & $\frac{6}{6}$ & $\stackrel{\infty}{\bullet}$ & 0 & 0 & 0 & $\%$ & \\
\hline \multirow[b]{2}{*}{$\varepsilon$} & \multirow[b]{2}{*}{$\stackrel{i}{w}$} & \multirow[b]{2}{*}{$\dot{\omega}_{\beth}$} & 40 & 58 & 52 & 22 & 14 & ك & \multirow{2}{*}{ 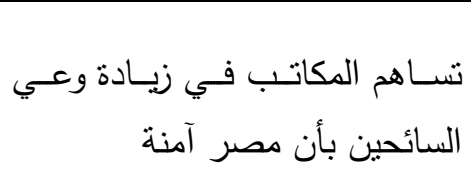 } \\
\hline & & & $\frac{N}{i r}$ & $\frac{\omega}{i}$ & $\infty$ & $\underset{\infty}{\varpi}$ & vir & $\%$ & \\
\hline \multirow[b]{2}{*}{0} & \multirow[b]{2}{*}{$\dot{w}$} & \multirow[b]{2}{*}{$\underset{\tilde{\sigma}}{\omega}$} & 48 & 30 & 44 & 40 & 24 & ك & \multirow{2}{*}{ 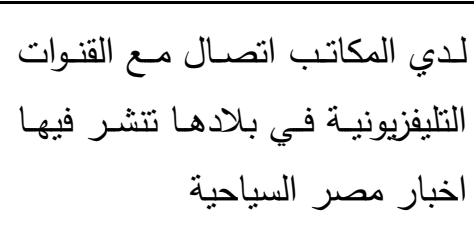 } \\
\hline & & & $\stackrel{N}{\infty}$ & $\ddot{a}$ & $\stackrel{N}{\omega}$ & $\frac{N}{i r}$ & $\stackrel{\sim}{0}$ & $\%$ & \\
\hline \multirow[b]{2}{*}{$\checkmark$} & \multirow[b]{2}{*}{$\dot{亠}_{\infty}^{\infty}$} & \multirow[b]{2}{*}{$\stackrel{\sim}{\perp}$} & 16 & 32 & 58 & 48 & 32 & ك & \multirow{2}{*}{ 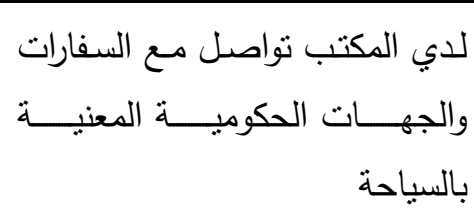 } \\
\hline & & & $\begin{array}{l}\infty \\
\dot{a}\end{array}$ & $\underset{v}{\sim}$ & $\underset{\omega}{\omega}$ & $\underset{\infty}{N}$ & $\underset{v}{\sim}$ & $\%$ & \\
\hline \multirow[b]{2}{*}{$\wedge$} & \multirow[b]{2}{*}{ ம் } & \multirow[b]{2}{*}{$\stackrel{\stackrel{N}{N}}{\stackrel{N}{N}}$} & 4 & 30 & 46 & 66 & 40 & ك & \multirow{2}{*}{ 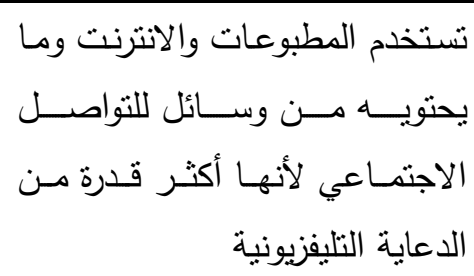 } \\
\hline & & & $\stackrel{\sim}{\dot{N}}$ & $\ddot{a}$ & $\stackrel{N}{\perp}$ & $\begin{array}{l}\text { ur } \\
\text { ur }\end{array}$ & $\stackrel{N}{i}$ & $\%$ & \\
\hline- & $\dot{\dot{0}}$ & $\dot{\omega}_{\infty}^{\omega}$ & \multicolumn{7}{|c|}{ الــــــوســــ الـحســــــــــــام } \\
\hline
\end{tabular}

"ك= تكرارات" 
يتضح أن اجابات أفراد عينة الدراسة محايدة على عبارات المحور الرابع (دور المكاتب الخارجية في تحسين الصورة الذهنية

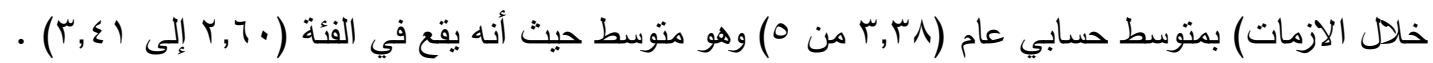
يتضح من النتائج أن أفراد عينة الدراسة يوافقوا بشدة على عبارة واحدة من عبارات المحور الرابع (دور المكاتب الخارجية في

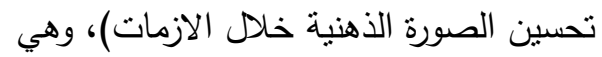

• عبارة "تروج المكاتب للاماكن السياحية البعيدة عن اماكن التوتز والمظاهرت كالبحر الاحمر والاقصر" بمتوسط

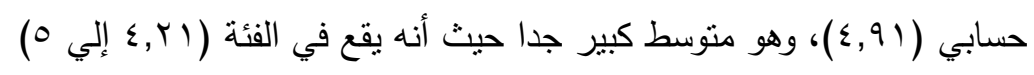

يتضح من النتائج أن أفراد عينة الدراسة يوافقوا على ثلاثة عبارات من عبارات المحور الرابع (دور المكاتب الخارجية في تحسين الصورة الذهنية خلال الازمات)، وهي

• عبارة "تظهر صورة مصر من خلال القنوات كمجتمع غير آمن يتعرض لضربات الإرهاب كل يوم" بمتوسط حسابي

• عبارة " توجد ردود أو تعقيبات من المكاتب عن كذب الادعاءات بأن شوارع مصر غير أمنة" بمنوسط حسابي

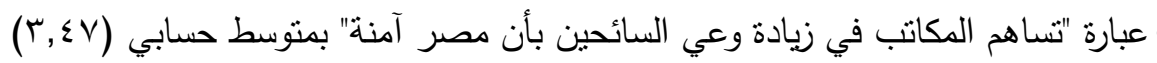

يتضح من النتائج أن أفراد عينة الدراسة إجاباتهم كانت محايدة على ثلاثة من عبارات المحور الرابع (دور المكاتب الخارجية

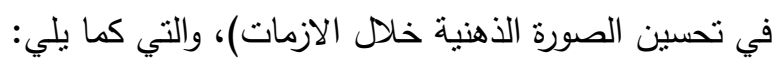

• عبارة "لدي المكاتب اتصال مع القنوات التليفزيونية في بلادها تتشر فيها اخبار مصر السياحية" بمتوسط حسابي

$$
\text { عبارة "تمتلك مصر صورة ذهنية جيدة أمام العالم" بمتوسط حسابي ( ( +, بـ) }
$$

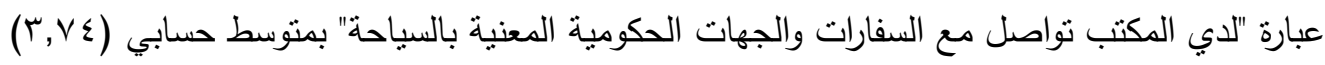

يتضح من النتائج أن أفراد عينة الدراسة لم يوافقوا على عبارة واحدة من عبارات المحور الرابع (دور المكاتب الخارجية في

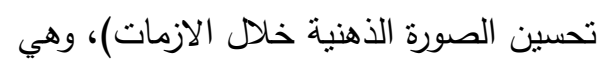

عبارة "نتتخدم المطبوعات والانتزنت وما يحتويه من وسائل للتواصل الاجتماعي لانها أكثر قدرة من الدعاية

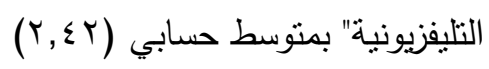

اتضح من الدراسة ان دور المكاتب الخارجية في تحسين الصورة الذهنية خلال الازمات هي الترويج للاماكن السياحية البعيدة عن اماكن التوتر والمظاهرت كالبحر الاحمر والاقصرثم العمل علي اظهار صورة مصر من خلال القنوات كمجتمع غير آمن

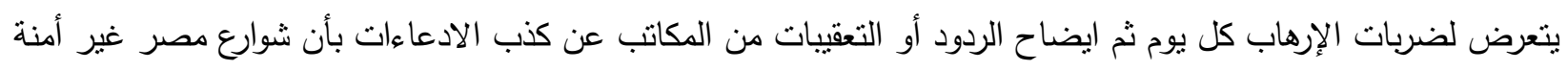

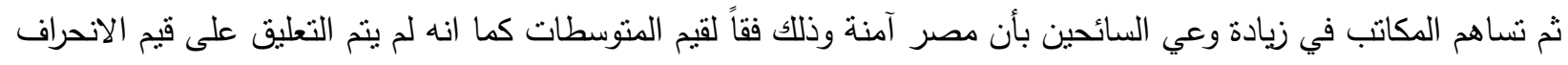

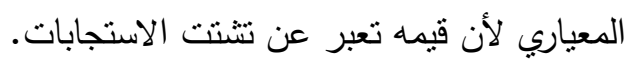




\section{ثالثاً: النتائج العامة للاراسة}

من خلال الدراسة الميدانية تم التوصل إلى مجموعة من النتائج لعل أبرزها:

1. أ. هناك خطط ترويجية عامة تتمثل فيما يلي:

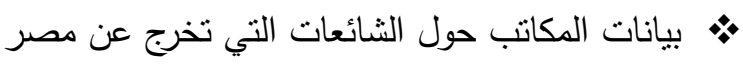

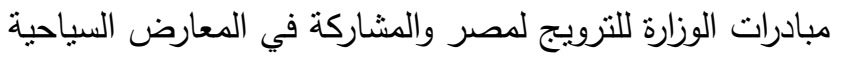

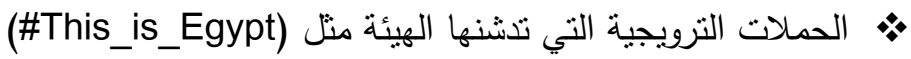

المنشورات الورقية التي يتم توزيعها على مكاتب السياحة الخارجية من خلال الهيئة

النترويج لمصر من خلال قنوات فضائية عالمية.

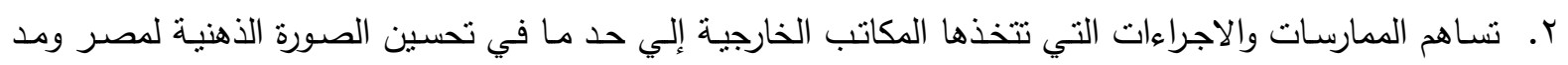
المتعاملين معها بالنشرات السياحية الجديدة وتحدد الانماط السياحية المناسبة لكل سوق.

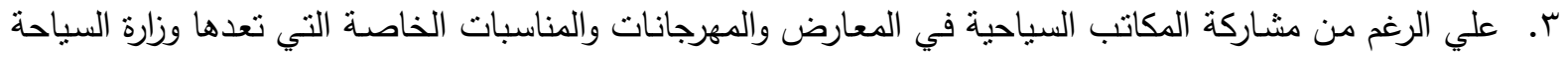

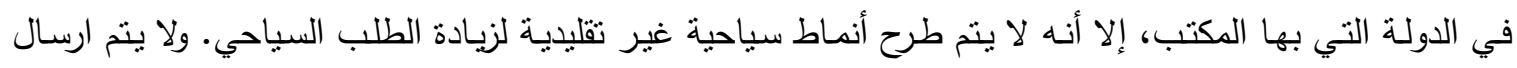
قوافل سياحية للاول المستهدفة.

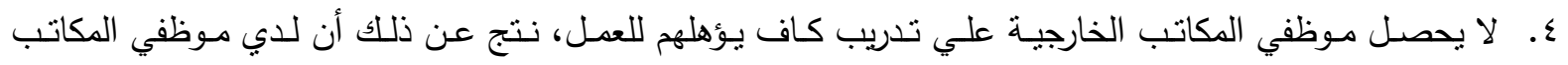
الخارجية قدرة بسيطة علي تسويق الأماكن السباحية في مصر وأنهم ليسوا مؤهلين بالقدر الكافي لإدارة الأزمات

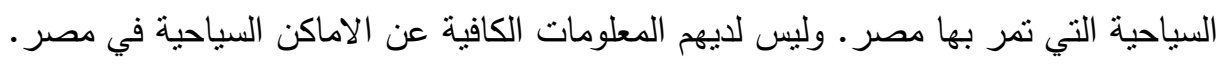
ه. لا يشترط لتعيين موظفي المكاتب الخارجية الحصول على مؤهل سياحي مما قد يؤثر علي مستوي كفاءتهم.

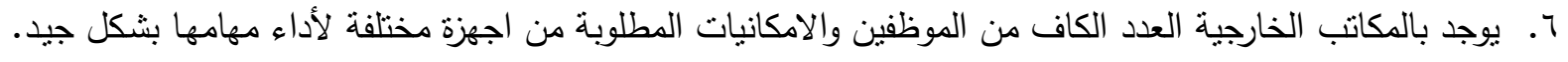

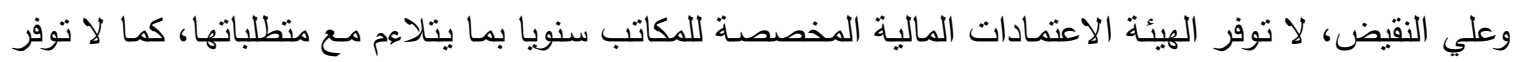

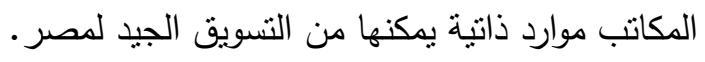

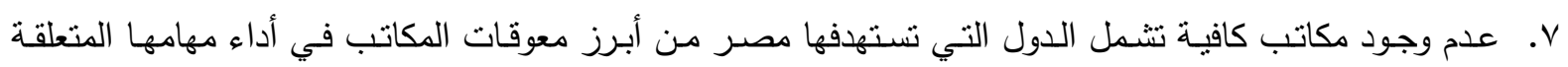
بتحسين الصورة الذهنية لمصر في فترة الأزمات التي تمر بها مع عدم كفاية التمويل المخصص لذاتلك، وكذللك عدم فاعلية الاساليب التزويجية المطبقة.

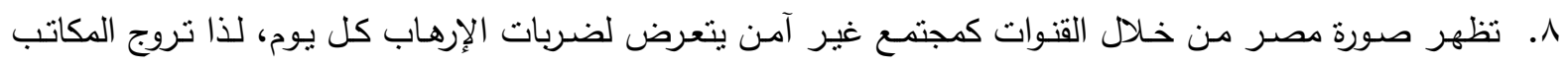

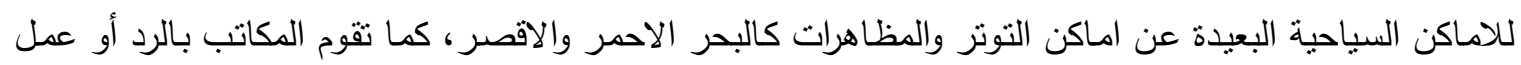

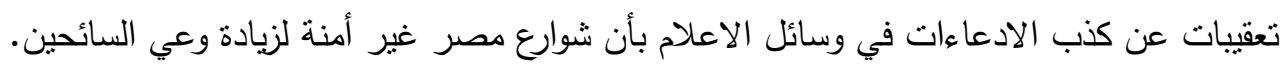

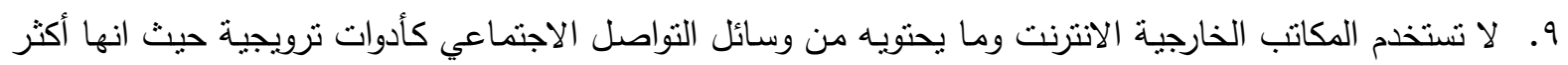

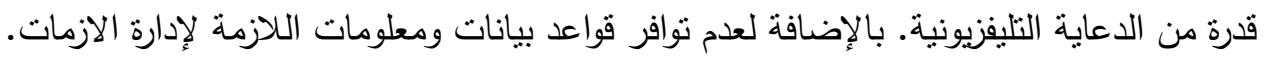
• 1. لا تقوم المكاتب الخارجية بتظيم ورش عمل وندوات مع كبري شركات الطيران ومنظمي الرحلات الثاميلة للتعريف

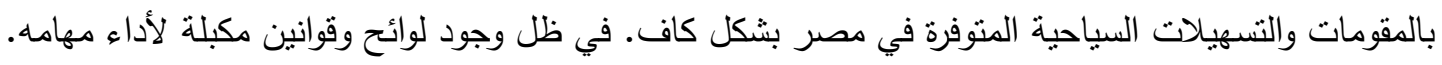


1 الـ لا تستطيع المكاتب الخارجيـة بالاتصـال بـالقنوات التليفزيونيـة التي تتشـر اخبار مصـر السياحية بصفة مسـتمرة أو التواصل مع السفارات والجهات الحكومية المعنية بالسياحة لتحسين الصورة الذهنية للمقصد السياحي المصري. r ا ـ لا تقيم المكاتب حفلات استقبال للتعرف علي رجال الإعلام السياحي ومنظمي الرحلات الثـاملة والجهات المعنية الأخرى بصفة دائمة ولا تصدر نشرات إخبارية توزع عليهم.

\section{رابعاً: توصبات الدراسة}

بناءً علي النتائج الي تم استخراجها من الدراسة الميدانية تم وضـع مجموعة من التوصيات الهامة التي قد تساعد علي تفعيل دور المكاتب الخارجية للهيئة المصرية العامة للتشيط السياحي في استعادة الصورة الذهنية للمقصد السياحي خلال الأزمات

ا ـ ــرورة التتسيق بين الهيئة المصـرية العامـة للتنشيط السياحي والهيئة المصـرية العامـة للاستعلامات لنشـر كافـة

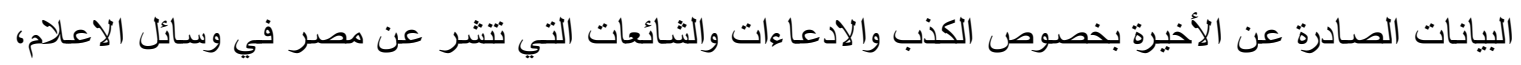
وذللك عن طريق المكاتب الخارجية للايئة باللغات المختلفة.

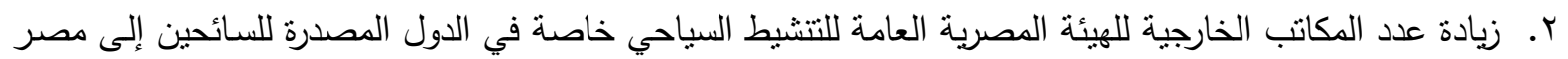
والأسواق السياحية المستهدفة. r. طرح انمـاط سياحية غير تقليديـة لزيـادة الطلب السياحي من خـلال المعـارض والمهرجانـات والقوافل والمناسبات السياحية الخاصة التي نتارك بها المكاتب الخارجية للهيئة ع. . التتسيق بين وزارتي الخارجية (منمنلة في السفارات المصرية بالخارج) والسياحة (متمنلة في للمكاتب الخارجية للهيئة المصرية العامة للتنشيط السياحي) لتحسين الصورة الذهنية عن المقاصد السياحية المصرية. كما يقترح أن يتم توفير مكتب للعيئة داخل السفارات لتسـهيل عمليـة التتسيق والتواصل، والرد على الاستقسارات السياحية من قبل زائري السفارة في بعض الدول التي تتطلب تأثيرة مسبقة لاخول مصر . ه. توفير دورات تدريبية لموظفي المكاتب الخارجية للهيئة المصرية العامة للتشيط السياحي عن كيفية تحسين الصورة الذهنية للمقصد السياحي المصري وإدارة الأزمات السباحية واثراء المعلومات السياحية المستحدثة بالمقصد السياحي المصري 7. إلزام المكاتب الخارجيـة للهيئة المصرية العامـة للتشيط السياحي بتقديم تقارير دوريـة عن الصـورة الذهنية للمقصد

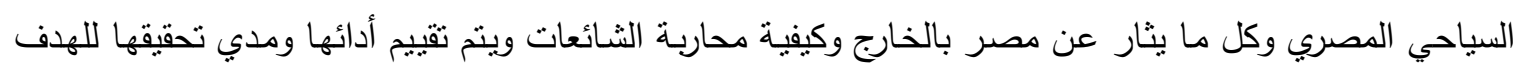
المرجو منها بصفة دورية. V. تعيين موظفين مؤهلين سياحياً لإدارة الأزمات السياحية ويفضل من يمنهم التحدث بأكثر من لغـة وقادرين على لـى التقاوض السياحي حتى يمكن استخدامهم في الاقاليم السياحية المستهدفة حول كل مكتب خارجي

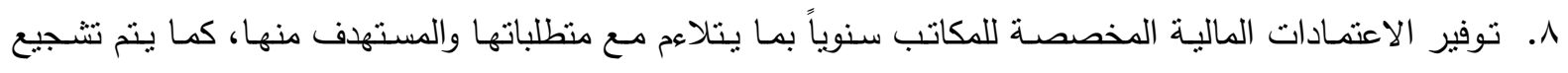

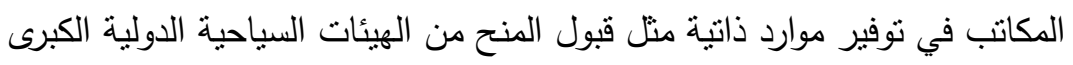
9 9. تتجيع المكاتب الخارجية على استخدام الانترنت وما يحتويه من وسائل التواصل الاجتماعي كأدوات ترويجية حيث انها أكثر قدرة من الدعاية التليفزيونية. والعمل على توافر قواعد بيانات ومعلومات اللازمة لإدارة الازمات. 
• ا ـ نوجيه المكاتب الخارجية بتتظيم ورش عمل وندوات مـع كبري شركات الطيران ومنظمي الرحلات الثـاملة للتعريف بالمقومات والتسهيلات السياحية المتوفرة في مصر بشكل منتظم.

11 ا ـ منح المكاتب الخارجية العديد من التسهيلات الدستورية والقانونية حتى لا يتم تقيض اداء عمله. r ا. نوجيه المكاتب الخارجية بالاتصال بالقنوات التليفزيونية التي تتشر اخبار مصر السياحية بصفة مستمرة والتواصل مع السفارات والجهات الحكومية المعنية بالسياحة لتحسين الصورة الذهنية للمقصد السياحي المصري.

سا ـ تتظيم المكاتب حفلات استقبال للتعرف على رجال الإعـلام السياحي ومنظمي الرحلات الثـاملة والجهات المعنية الأخرى بصفة دائمة واصدار نشرات سياحية توزع عليهم.

\section{المراجع العربية}

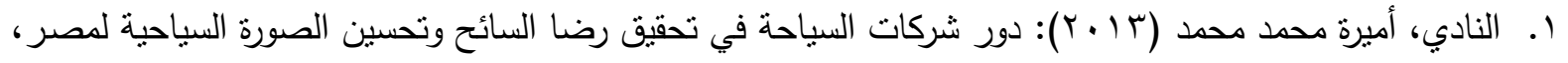
رسالة دكتوراه، قسم الدراسات السياحية، كلية السياحة والفنادق، جامعة قناة السويس. r. مرسي، حنيفة ( . . . r): دور المكاتب السياحية المصرية في الخارج التمنيل السياحي الخارجي، طوخي مصر للنشر وللطباعة، القاهرة.

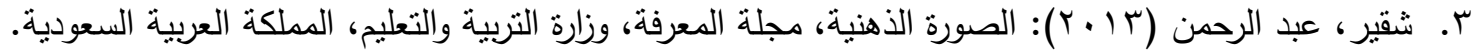

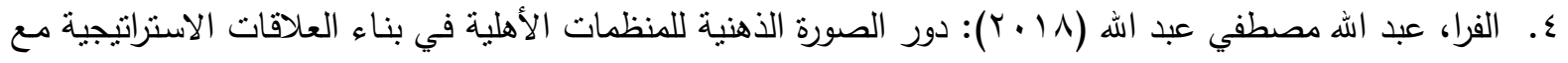

جمهور المستقيدين، رسالة ماجسنير غير منشورة، قسم إدارة الأعمال، كلية التجارة، الجماعة الإسلامية، غزة.

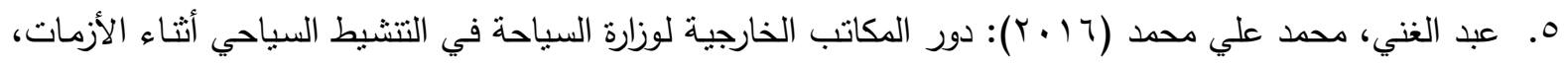
رسالة ماجستير، قسم الدراسات السياحية، كلية السياحة والفنادق، جامعة قناة السويس.

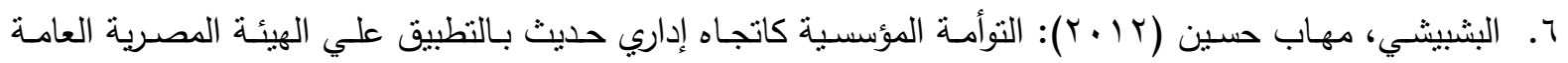

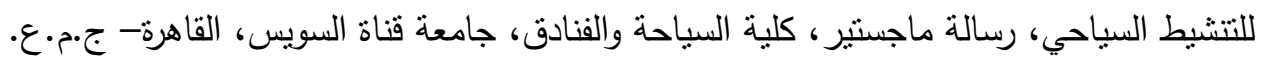

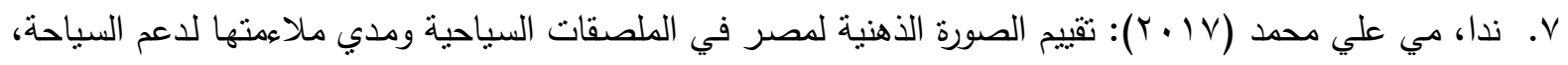

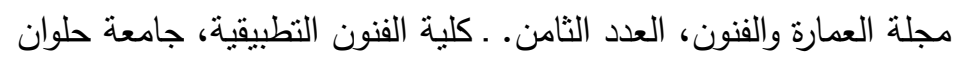

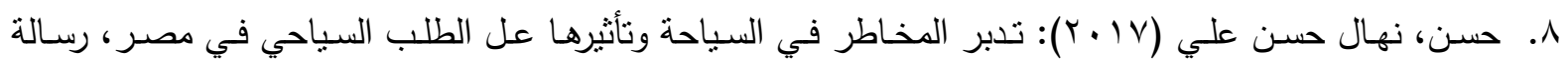
ماجستير، قسم الدراسات السياحية، كلية السياحة، جامعة قناة السويس.

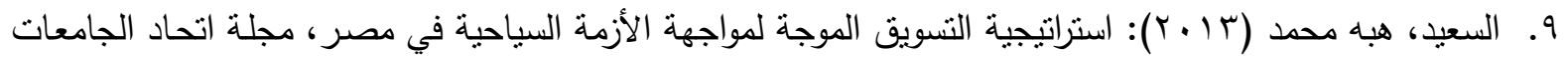
العربية للسياحة والضيافة، مجلد · (، عدد خاص، كلية السياحة والفنادق، جامعة قناة السويس، ديسمبر ، مصر .

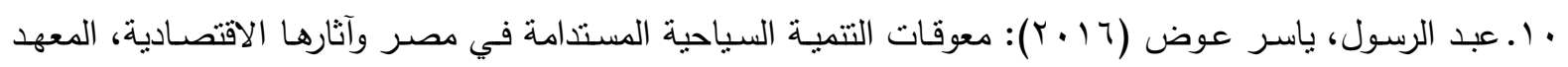
العالي للإدارة والحاسب الآلي براس البر، دمياط.

11. Ayish, M., (2005): Virtual Public Relations in The United Arab Emirates: A Case Study of 20 UAE Organization, Use of The Internet, Public Relation Review, UK.

12. Soliman, Mohammad, Marwa S.Wahba (2018): Investigating influencers of employee engagement in travel agents in Egypt, Egypt. 